\title{
Elevation of Brain Magnesium Prevents and Reverses Cognitive Deficits and Synaptic Loss in Alzheimer's Disease Mouse Model
}

\author{
Wei Li, ${ }_{1}^{1}$ Jia Yu, ${ }^{2}$ Yong Liu, ${ }^{3}$ Xiaojie Huang, ${ }^{1}$ Nashat Abumaria, ${ }^{1}$ Ying Zhu, ${ }^{1}$ Xian Huang, ${ }^{1}$ Wenxiang Xiong, ${ }^{1}$ Chi Ren, ${ }^{1}$ \\ Xian-Guo Liu, ${ }^{3}$ Dehua Chui, ${ }^{2}$ and Guosong Liu ${ }^{1,4}$ \\ ${ }^{1}$ Tsinghua-Peking Center for Life Sciences, School of Medicine, Tsinghua University, Beijing 100084, China, ${ }^{2}$ Neuroscience Research Institute, Health \\ Science Center, Peking University, Beijing 100191, China, ${ }^{3}$ Department of Physiology, Zhongshan School of Medicine, Sun Yat-sen University, Guangzhou \\ 510080, China, and ${ }^{4}$ Center for Learning and Memory, University of Texas at Austin, Austin, Texas 78712
}

Profound synapse loss is one of the major pathological hallmarks associated with Ah eim s disease (AD) and might underlie memory impairment. Our previous work demonstrated that the magnesium ion is a criti a facto n co colling synapse density/plasticity. Here, we investigated whether elevation of brain magnesium by the use of a recently a loped co pound, magnesium-L-threonate $(\mathrm{MgT})$, can ameliorate the AD-like pathologies and cognitive deficits in the APPswe/PS1dE9 ice, a transgenic (Tg) mouse model of AD. MgT treatment reduced $\mathrm{A} \beta$ plaque and prevented synapse loss and memor decline in the Tg mice. Strikingly, $\mathrm{MgT}$ treatment was effective even when given to the mice at the end stage of their AD-like patholo ical prog ession. To explore how elevation of brain magnesium ameliorates the AD-like pathologies in the brains of Tg mice, wa studied ole nes critical for APP metabolism and signaling pathways implicated in synaptic plasticity/density. In the Tg mice, the TML/CREB/BDNF signaling was downregulated, whereas calpain/ calcineurin/Cdk5 neurodegenerative signaling and $\beta$-sentase $1 \mathrm{CE1}$ ) expression were upregulated. MgT treatment prevented the impairment of these signaling pathways, stabilized B $\alpha$ E1 e press n, and reduced soluble APP $\beta$ and $\beta$-C-terminal fragments in the Tg mice. At the molecular level, elevation of extracellna $n$ a sestum prevented the high-A $\beta$-induced reductions in synaptic NMDARs by preventing calcineurin overactivation in hipp ampal s. Correlation studies suggested that the protection of NMDAR signaling might underlie the stabilization of BACE1 express n. Our results suggest that elevation of brain magnesium exerts substantial synaptoprotective effects in a mouse model of $A$ and may ve therapeutic potential for treating $\mathrm{AD}$ in humans.

\section{Introduction}

Dysfunctions in the metabolic cesses of APP are widely hypothesized to underlie Alzheime disease (AD) (Holtzman et al., 2011; Selkoe, 2011). In this scenario, increases in concentration of several potentially toxic peptides, including soluble APP $\beta$ $(\operatorname{sAPP} \beta)$ and $\beta$-C-terminal fragments $(\beta$-CTFs; Tamayev et al., 2012), $N$-APP (Nikolaev et al., 2009), and small A $\beta$ oligomers, lead to the formation of $A \beta$ plaques, synapse dysfunction/loss, neuronal loss, and overall brain atrophy, which cause decline of cognitive abilities (Jack et al., 2010; Selkoe, 2011). Therefore,

Received Sept. 27, 2012; revised April 3, 2013; accepted April 5, 2013.

Author contributions: W.L., N.A., X.-G.L., and G.L. designed research; W.L., J.Y., Y.L., Xiaojie Huang, Y.Z., Xian Huang, W.X., C.R., and D.C. performed research; W.L., J.Y., and C.R. analyzed data; W.L., N.A., and G.L. wrote the paper.

This work was supported by the National Basic Research Program of China (Grant 2009 CB941303 and Grant 2011 (B302201 to G.L.), and Grant 2013CB835102 to N.A., and the National Natural Science Foundation of China (Grant 30970957 to X-G. L.).We thank Jack L. Feldman for comments on the manuscript and Jiangyang Lu for technical support in electron microscopy.

G.L. is a cofounder of Magceutics, a company that develops drugs to treat age-dependent memory decline and Alzheimer's disease, and has a U.S. patent application on "MgT. " The remaining authors declare no competing financial interests.

Correspondence should be addressed to Guosong Liu, Tsinghua-Peking Center for Life Sciences, School of Medicine, Tsinghua University, Beijing 100084, China. E-mail: liu.guosong@gmail.com.

DOI:10.1523/JNEUROSCI.4610-12.2013

Copyright $\odot 2013$ the authors $\quad 0270-6474 / 13 / 338423-19 \$ 15.00 / 0$ designing therapeutic agents that target APP metabolic processes is among the major strategies being pursued in the quest to treat AD (Holtzman et al., 2011). However, these agents have not been shown to slow/reverse the cognitive deficits in $\mathrm{AD}$ patients (Holtzman et al., 2011).

Although dysfunctions in APP metabolism are a strong predictor for developing $\mathrm{AD}, \mathrm{A} \beta$-plaque density does not always correlate with the decline in cognitive abilities (Terry et al., 1991). For example, some A $\beta$-plaque-positive subjects have no signs of brain atrophy (Savva et al., 2009), and highly educated subjects seem to tolerate high levels of $\mathrm{A} \beta$ plaques without cognitive impairment (Roe et al., 2008). Therefore, although dysfunctions in APP metabolism might be necessary, they do not appear to be sufficient to cause $\mathrm{AD}$-associated atrophy and cognitive impairment (Sperling et al., 2011).

Numerous studies demonstrate that elevation of soluble $A \beta$ in the brain could impair synaptic function and reduce synapse density (Palop and Mucke, 2010; Selkoe, 2011). However, synaptic plasticity and density are regulated by numerous endogenous factors (Greer and Greenberg, 2008), with some having neurotrophic/synaptotrophic functions. Therefore, a balance between APP-derived neurotoxic peptides and neurotrophic/ synaptotrophic factors might ultimately determine the rate of 
decline in synaptic and cognitive functions in $\mathrm{AD}$. Indeed, several endogenous neurotrophic factors are effective in counteracting the synapse and memory loss in animal models of AD. For example, administration of the peptide cerebrolysin (Rockenstein et al., 2003), the octapeptide NAPVSIPQ (Matsuoka et al., 2008), nerve growth factor (De Rosa et al., 2005), and brain infusion of brain-derived neurotrophic factor (BDNF) (Nagahara et al., 2009) have all been shown to reverse synapse loss or rescue learning and memory in rodent and primate AD models. In humans, intranasal administration of insulin improves cognition in early AD (Reger et al., 2008). Therefore, protecting existing synapses and/or promoting synapse generation/regeneration by increasing trophic factors in the brain might present an alternative strategy to ameliorate memory deficits in AD.

Our previous studies indicated that the magnesium ion $\left(\mathrm{Mg}^{2+}\right)$ is a critical factor in controlling synapse density/plasticity (Slutsky et al., 2004). We have shown that elevation of brain magnesium by the use of a novel compound, magnesium-Lthreonate (MgT), upregulates NMDAR signaling, prevents synapse loss, and reverses memory deficits in aged rats (Slutsky et al., 2010). If impairment in cognitive functions in AD patients is mainly caused by synapse failure/loss (Selkoe, 2002), it is relevant to determine whether elevation of brain magnesium could still be effective under AD-like pathological conditions. Furthermore, brain magnesium levels (Andrási et al., 2005) and serum $\mathrm{Mg}^{2+}$ concentrations (Barbagallo et al., 2011) appear to be significantly lower in $\mathrm{AD}$ patients compared with age-matched normal subjects. If this is the case, then simply restoring brain magnesium might beneficiate AD patients. Here, we show that elevation $f$ brain magnesium prevents/reverses synapse loss and memo deficits in a transgenic mouse model of AD and reveal thanossi ble underlying mechanism.

\section{Materials and Methods}

Experimental animals

Six hemizygous transgenic male mice (APPsw ferred to hereafter as Tg mice) and six obtained and bred in Peking University' cording to protocol provided by the sur In the breeding colony, a total of typed routinely to identify the

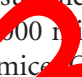
00 ice

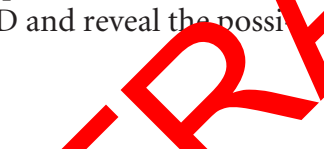
(WT) and $\sim 250$ male Tg mice wer separed and the majority of them were used in the present study. Anim were housed individually in a controlled environment (temperature $2 \mathrm{Y} \pm 1{ }^{\circ} \mathrm{C}$, humidity $50 \pm 10 \%$ ) under an inverted light cycle (lights off 9:00 A.M. to 9:00 P.M.). Behavioral experiments were performed under dim red light. All experiments were performed on male mice except Western blot experiments in which female mice were used (WT: $n=48$; Tg: $n=48$ ). To conduct molecular, cellular, and structural analyses, animals were killed at ages of 15, 18, 23, or 24 months (for details on each experiment, see the Results section). Experiments involving animals were approved by the Tsinghua University and Peking University committees on animal care.

\section{Treatment with $\mathrm{MgT}$}

$\mathrm{Tg}$ and WT mice received $\mathrm{MgT}$ (Magceutics) treatment via drinking water at a dose of $\sim 910 \mathrm{mg} / \mathrm{kg} / \mathrm{d}(\sim 75 \mathrm{mg} / \mathrm{kg} / \mathrm{d}$ elemental magnesium). This dose was determined by scaling the minimum effective dose in rats as described previously (Slutsky et al., 2010). To monitor the dose of MgT $(\mathrm{mg} / \mathrm{kg} / \mathrm{d})$, water intake and body weight were measured on daily basis (at 8:30 P.M.). The amount of MgT necessary to reach the target dose was calculated based on body weights and dissolved in the daily drinking water ( $\sim 6 \mathrm{ml} / \mathrm{d} /$ mouse) of individual animals. The MgT treatment was started when the mice were 6 months of age and lasted until animals were killed. This does not include the end-stage treatment experiments (Fig. $9 A-H)$, during which $\mathrm{MgT}$ treatment was given to Tg mice at age of 23 months for 1 month only. Untreated WT and Tg mice received tap water.
All mice were maintained on standard food containing $0.15 \%$ elemental magnesium.

\section{Magnesium measurement in body tissues and fluids}

To determine the total magnesium content (ionized and nonionized) in different body tissues, mice were transcardially perfused and then different body tissues such as kidney, liver, muscles, fur, heart, and brain, were analyzed. Total magnesium content in the different tissues was measured using inductively coupled plasma optical emission spectroscopy (Chemical Analysis Center, Tsinghua University). To determine the free $\mathrm{Mg}^{2+}$ concentration in the plasma and intracellular compartment of red blood cells (RBCs), blood samples were collected from the orbital sinus, centrifuged, and plasma was collected for measurement immediately. $\mathrm{Mg}^{2+}$ concentration in the plasma was measured using Calmagite chromometry as described previously (Slutsky et al., 2010). The intracellular $\mathrm{Mg}^{2+}$ concentration in RBCs (Fig. $1 H$ ) was determined by flow cytometry (Center for Biomedical Analysis, Tsinghua University). The fluorescent optical density (OD) was used as an indicator of the $\mathrm{Mg}^{2+}$ concentration in RBCs. The data presented represent the average of OD of 10,000 RBCs for each mouse.

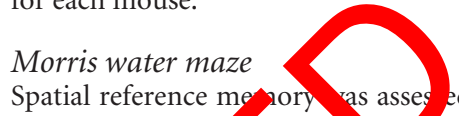

Spatial reference me yory as asse ed using a modified version of the Morris water mar (Morris al 982). The pool was a circular metal tank $100 \mathrm{~cm}$ in tame $\mathrm{c}, 50 \mathrm{~cm}$ deep, filled to a height of $35 \mathrm{~cm}$ with water. Wat tem $_{\mathrm{P}}$ ature s maintained at $21 \pm 1^{\circ} \mathrm{C}$. An acrylic platform (10 in dian was placed inside the pool with its surfacer $\mathrm{cm}$ ow the surface of the water so that a mouse inside the pool wo unable locate it visually. The pool was set in a moderately lit, rcular enclosure made with black curtains. Four cues with different ape and $\$$ lor were placed within the maze and the other four cues were p. ed ex mally on the curtains. These cues remained unchanged througrrout the testing period. The combination of proximal and distal cun was used based on pilot experiments during which we tested the sensitivity of WT mice to distal and proximal cues. Under our experimental conditions, the optimal learning curve for naive WT mice (declining from $\sim 60 \mathrm{~s}$ to $<20 \mathrm{~s}$ over the time course of training) was obtained upon combining proximal and distal cues. Two protocols were used. For the first protocol, at 7 months of age, mice received the visible platform training session for $1 \mathrm{~d}$ (day 0 ). This session was followed by hidden platform training session for $5 \mathrm{~d}$ with 5 trials/day $(60 \mathrm{~s} /$ trial, $1 \mathrm{~h}$ intertrial interval). Each mouse was placed into the water by hand so that it faced the wall of the pool at one of four starting positions. The sequence of these positions was randomly selected. The platform was set in the middle of one quadrant equidistant from the center and the edge of the pool. If the mouse found the platform, it was allowed to remain there for $30 \mathrm{~s}$ and was then returned to its home cage. If the mouse was unable to find the platform within $60 \mathrm{~s}$, it was guided to and placed on the platform for $30 \mathrm{~s}$, the trial was terminated, and the maximum score of $60 \mathrm{~s}$ was given. In each trial, the latency to locate the hidden platform was recorded using a video tracking system (EthoVision; Noldus). The test trial (the memory retention test) was performed $24 \mathrm{~h}$ after the last trial of the training session. During the test trial, the platform was removed and each mouse was put into the pool for $60 \mathrm{~s}$. The total time spent in the target quadrant (where the platform had been located during the training trials) was measured using the same video system. Experiments and video analysis were performed by experimenters who were unaware of the treatment and genotype of each group.

For the second protocol, at 15 months of age, we modified the water maze protocol to increase the task's difficulty. The tank diameter was increased to $120 \mathrm{~cm}$ with a $12 \mathrm{~cm}$ diameter platform under an open environment (i.e., the curtains were removed) around the water maze. Mice were trained for $4 \mathrm{~d}$ ( 6 trials/day, $60 \mathrm{~s} /$ trial, $1 \mathrm{~h}$ intertrial interval).

\section{Novel object recognition task}

A modified version of the novel object recognition test (NORT; Ennaceur and Delacour, 1988) was used to evaluate short-term memory (STM) and long-term memory (LTM). The apparatus consisted of a square arena $(50 \times 50 \times 20 \mathrm{~cm})$ made of polyvinyl chloride with white walls and floor. An overhead camera and a video recorder were used to 

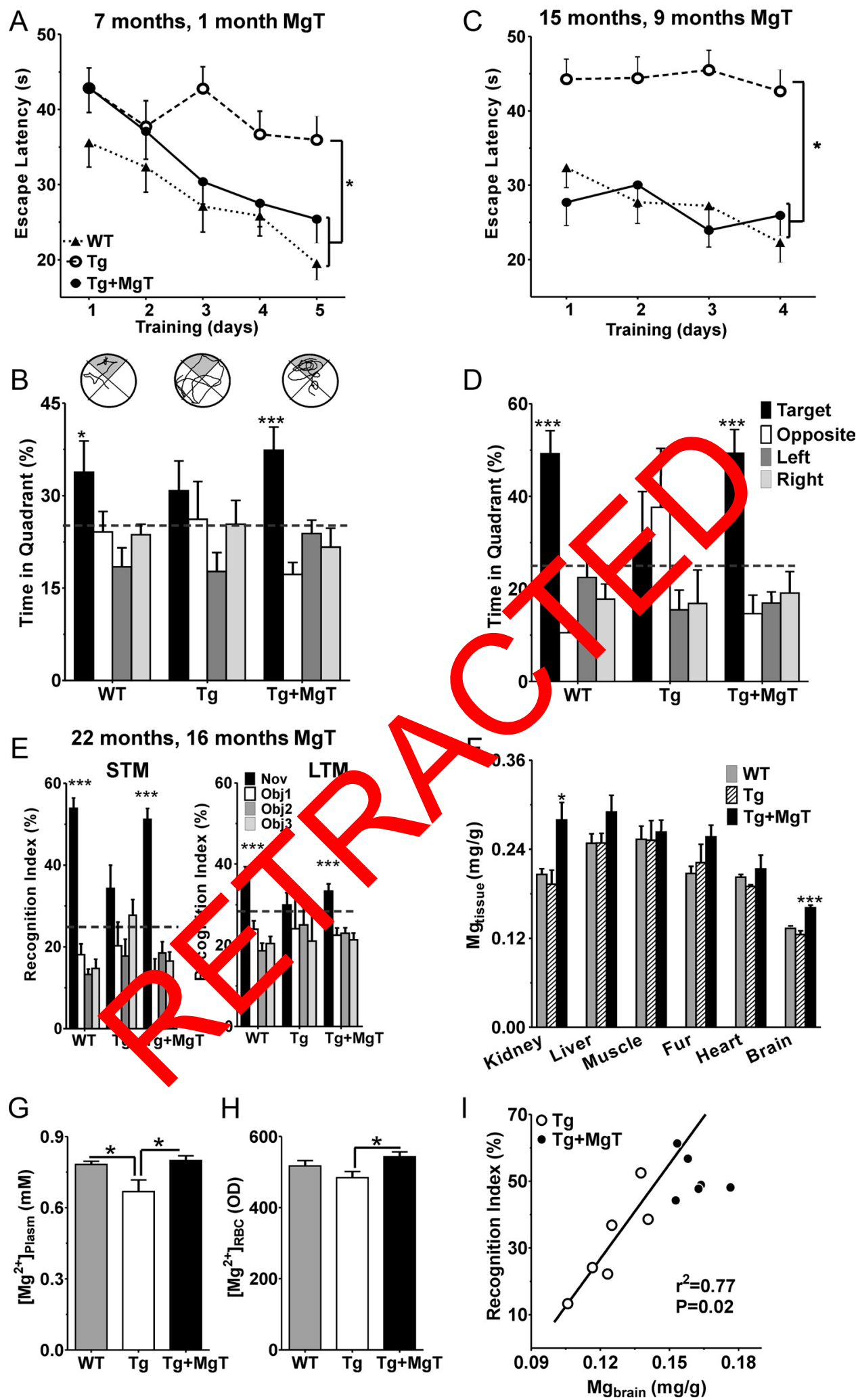

Figure 1. Prevention of memory deficits in $\mathrm{Tg}$ mice by MgT treatment. $A$, Escape latencies in seconds (s) during training ( 5 trials/d) in water maze task at 7 months of age (i.e., after 1 month of treatment). Three groups of mice were used: WT $(n=9), \operatorname{Tg}(n=13)$, and $\mathrm{Tg}+\mathrm{MgT}(n=9)$ (ANOVA effect of treatment, $p<0.05)$. $\boldsymbol{B}$, Probe test conducted $24 \mathrm{~h}$ after the training. Top, Representative path tracings. Bottom, Percentage of time spent in each quadrant (ANOVA differences among quadrants: WT: $p<0.05 ; \mathrm{Tg}+\mathrm{MgT}: p<0.0001$ ). $C$, Same as $A$ and on the same mice, but tested at 15 months of age (WT, $n=9 ; \mathrm{Tg}, n=7 ; \mathrm{Tg}+\mathrm{MgT}, n=6$; ANOVA effect of treatment, $p<0.05$ ). D, Probe test $24 \mathrm{~h}$ later (ANOVA differences among quadrants: WT: $p<0.0001$; $\mathrm{Tg}+$ MgT: $p<0.0001)$. E, STM (10 min retention interval, left) and LTM (24h, right) NORTs performed on the same group of mice at 22 months of age (WT, $n=7 ; \mathrm{Tg}, n=6 ; \mathrm{Tg}+\mathrm{MgT}, n=6)$. Recognition index calculated as percentage of time spent exploring each object (0bj1-3). Black bars indicate novel object (Nov). ANOVA differences in recognition index of different objects in WT (STM: $p<0.0001$; LTM: $p<0.0001$ ) and Tg + MgT (STM: $p<0.0001$; LTM: $p<0.001$ ). Dashed lines represent chance levels of performance (25\%). $\boldsymbol{F}$, Total magnesium (ionized and nonionized) contents in different organs/tissues ( $\mathrm{Mg}_{\text {tissue }}$ ) normalized to tissue weight $(\mathrm{mg} / \mathrm{g})$ in the same groups of mice (WT, $n=7 ; \mathrm{Tg}, n=6 ; \mathrm{Tg}+\mathrm{MgT}, n=6$; (Figure legend continues.) 
monitor and record the animal's behavior for subsequent analysis. Two days before the experiment, all mice received two sessions of habituation to the arena and test room $10 \mathrm{~min} / \mathrm{session} / \mathrm{d}$. At day 3, each mouse was placed in the center of the box, exposed to 4 identical objects for $5 \mathrm{~min}$ (sample phase), and then returned to its cage. For STM, a 5 min retention interval was used, during which 1 of the objects was replaced by a new novel object. The objects were placed in the same locations as the previous ones. The mice were placed back in the box and exposed to the 3 familiar objects and to the novel object for further 5 min (test phase). During this phase, the mouse explored each of the 4 objects. The exploration of an object was defined as directing the nose to the object at a distance of $2 \mathrm{~cm}$ and/or touching it with the nose and forepaws. Turning around the object without direct exploration was not considered. The session was recorded on video and the frequency of object exploration was subsequently measured by experimenters who were unaware of the treatment and genotype of each group. Recognition index was calculated as percentage ratio of time of each object over total exploration time. The box and objects were cleaned with $20 \%$ ethanol between trials to prevent the buildup of olfactory cues. For LTM tests, the same procedure was used but the retention interval was $24 \mathrm{~h}$ and completely different objects were used.

\section{Nest construction test}

Mice were individually housed in plastic cages with $\sim 1 \mathrm{~cm}$ of woodchip bedding lining the floor. Two hours after the onset of the dark phase, individual cages were supplied with a $20 \times 20 \mathrm{~cm}$ piece of paper towel torn into $\sim 5 \times 5 \mathrm{~cm}$ square pieces. Cages were observed for the next $12 \mathrm{~h}$. Pictures were taken for documentation before the evaluation. Nest construction was scored along a system as follows: $1=$ no biting or tears on the paper, 2 = mild biting and/or tears without gathering, $3=$ moderate biting and/or tears on the paper with moderate gathering of pieces, $4=$ the majority of papers torn and gathered in a good manner, and $5=$ the vast majority of papers were torn into $\sim 1 \mathrm{~cm}$ pieces and grouped int corner of the cage. Twenty-four hours after the first nest constructio test, MgT treatment of the $\mathrm{Tg}$ mice started and lasted for which time the second test was conducted. Mice were tes balanced groups of mixed genotypes. Nest constructi experimenters who were unaware of the treatment $a$ group.

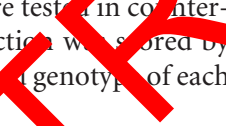

tone dilutions and flat embedded in Epon resin. Semithin sections (500 $\mathrm{nm}$ ) stained with toluidine blue were used to locate and trim the granule cell layer and molecular layer of dentate gyrus (DG) in the hippocampus. Ultrathin sections $(60 \mathrm{~nm})$ stained with uranyl acetate and lead citrate were examined with a JEOL model 1200EX transmission electron microscope operated at $80 \mathrm{kV}$. Two sets of images were randomly captured at magnifications of 12,000 and 30,000, respectively. Scale bars were taken from scans of original electron micrograph negatives. Quantitative analysis was conducted on the digital electron micrographs of the same magnification from the outer molecular layer of the hippocampus DG from all mice. The measurement was performed by experimenters who were unaware of the treatment and genotype of each group and was assisted by MetaMorph software (Molecular Devices). Synapses were identified on the micrographs by the presence of postsynaptic density and at least two synaptic vesicles in the axon terminal in close proximity. For the analysis of the synaptic density, the sets of lower-magnification micrographs were used (24-26 micrographs for each mouse).

\section{Estimation of density of presynaptic puncta}

Density of synaptophysin-//ar glutamate transporter 1 (VGluT1)/ glutamic acid decarbox ase 65 a (GAD65)/vesicular acetylcholine transporter (vAChT)-im unoreact e presynaptic terminals were quantified as described cvious), or sy aptophysin-positive puncta (Slutsky et al., 2010). Co nal se cons ( m thick) from the left hemisphere were deparaffinize in $v$ and ehydrated using a descending ethanol series folloy by ept e r ieval with citrate buffer. After blocking with $5 \%$ no als um (frol the host of the secondary antibody) in PBS with $0.1 \%$ Triton $\mathrm{X} 00$, tissue sections were incubated overnight with the mary antibody (ror detailed information on each antibody, see Table 1) in BS with 3 serum at $4^{\circ} \mathrm{C}$. After washing in PBS, sections were incubated th $\mathrm{CF}^{488}$ onjugated (Biotium) secondary antibody (Table 1). After washing 1 S, sections were coverslipped with anti-fade mounting medium Actashield; Vector Laboratories). Slides were coded until the completion of data analysis. Stained brain sections were imaged with an Olympus model IX-70 confocal microscope with the $60 \times$ water lens (numerical aperture $=1.2$ ) at a $3 \times$ zoom, generating an image with $78.6 \times 78.6 \mu \mathrm{m}$ dimensions. Serial $z$-sectioning was performed (thickness of $0.6 \mu \mathrm{m}$ ) and the best three $z$-sections (with highest number of puncta) were collected and merged into a single image. Therefore, the volume of brain tissue per image is $\sim 78.6 \times 78.6 \times 1.8 \mu \mathrm{m}^{3}$. The number of synapses in the DG and CA1 subregions was estimated from the obtained images using Image-Pro Plus version 6.0 software (MediaCybernetics). Background levels were equalized and special filters to separate fluorescent puncta were applied. Settings for each image were adjusted to maximize the number of detected fluorescent puncta. The mean puncta number per $1000 \mu \mathrm{m}^{2}$ was used as an estimate of the presynaptic puncta density.

\section{Amyloid plaque immunostaining}

Plaque burden was assessed by immunohistochemistry on paraffinembedded sections using monoclonal anti-A $\beta$ antibodies 4G8 and/or 6E10 (Signet), as described previously (Borchelt et al., 1997). Before immunostaining, sections were deparaffinized in xylene and washed in $100 \%$ ethanol, $95 \%$ ethanol, $70 \%$ ethanol, and water. Endogenous peroxidase activities in sections were quenched by 10 min incubations in $3 \%$ $\mathrm{H}_{2} \mathrm{O}_{2}$ in methanol followed by epitope retrieval with citrate buffer and 5 min incubation in $85 \%$ formic acid. After rinsing in PBS, nonspecific epitopes were blocked with normal horse serum and sections were incubated with primary antibody 4G8 and/or 6E10 (1:500 dilution) in PBS with $3 \% \mathrm{BSA}$ and incubated overnight at $4^{\circ} \mathrm{C}$ in a humid chamber. Sections were then washed in PBS and incubated with biotinylated secondary antibodies and avidin-biotin-peroxidase as described by the manufacturer (Vectastain Elite ABC Kit; Vector Laboratories) and visualized with diaminobenzidine tetrachloride. Stained sections containing hippocampus were examined with a Leica DM IRB inverted research microscope with a $5 \times$ objective, and digital images were captured with a Retiga 2000R digital camera and QCapture software (both from QImaging). The areas covered by amyloid plaque in the hippocampal formation

and frontal cortex were calculated using Image-Pro Plus software. The
(Figure legend continued.) ANOVA difference among groups: brain: $p<0.0001$; kidney: $p<$ $0.01) . G$, Magnesium ion concentration in the plasma $\left(\left[\mathrm{Mg}^{2+}\right]_{\text {plasma }}\right.$ mM) of WT $(n=14), \mathrm{Tg}$ $(n=9)$, and $\operatorname{Tg}+\operatorname{MgT}$ mice $(n=8)$ as measured by the calmagite method (ANOVA difference among groups, $p<0.01)$. $\boldsymbol{H}$, Intracellular free $\mathrm{Mg}^{2+}$ concentration in the $\mathrm{RBC}\left(\left[\mathrm{Mg}^{2+}\right]_{\mathrm{RBC}}\right)$ of WT $(n=12), \operatorname{Tg}(n=11)$, and $\mathrm{Tg}+\mathrm{MgT}$ mice $(n=11)$ as measured by the flow cytometry method (OD; ANOVA difference among groups, $p<0.05)$. ANOVA was followed by Bonferroni's post hoc test. I, Brain total magnesium content $\left(\mathrm{Mg}_{\text {brain' }} \mathrm{mg} / \mathrm{g}\right)$, in Tg mice (23 months old) significantly correlated with the recognition index in the STM test (Pearson's test). Data from $\mathrm{Tg}+$ MgT mice (23 months old treated for 17 months) are displayed, but were not included in the correlation analysis. Error bars show SEM. ${ }^{*} p<0.05 ;{ }^{* * *} p<0.001$. 
Table 1. Primary and secondary antibodies

\begin{tabular}{|c|c|c|c|c|}
\hline Experiments & Primary antibodies & Host & Dilution & Source \\
\hline \multirow[t]{34}{*}{ Quantitative immunostaining } & Synaptophysin & Mouse & 1:500 & Millipore \\
\hline & VGluT1 & Mouse & $1: 500$ & Millipore \\
\hline & GAD65 & Rabbit & $1: 500$ & Millipore \\
\hline & VAChT & Rabbit & 1:100 & Novus \\
\hline & NR2B & Rabbit & $1: 500$ & Millipore \\
\hline & pNR2B (Tyr1472) & Rabbit & $1: 50$ & Abcam \\
\hline & Camkll & Rabbit & $1: 50$ & Santa Cruz Biotechnology \\
\hline & pCamkII(Thr286) & Rabbit & $1: 100$ & Cell Signaling Technology \\
\hline & Calmodulin & Mouse & $1: 100$ & Invitrogen \\
\hline & Creb & Rabbit & 1:400 & Cell Signaling Technology \\
\hline & pCreb (Ser133) & Rabbit & $1: 25$ & Cell Signaling Technology \\
\hline & $\mathrm{Erk}_{1 / 2}$ & Mouse & $1: 25$ & Cell Signaling Technology \\
\hline & perk $_{1 / 2}\left(\right.$ Thr202/Tyr204) $^{2}$ & Mouse & $1: 400$ & Cell Signaling Technology \\
\hline & BDNF & Rabbit & $1: 50$ & Santa Cruz Biotechnology \\
\hline & TrkB & Rabbit & $1: 80$ & Cell Signaling Technology \\
\hline & pTrkB (Tyr816) & Rabbit & $1: 50$ & Novus \\
\hline & IRS-1 & Rabbit & 1:250 & Millipore \\
\hline & Akt & Mouse & & Cell Signaling Technology \\
\hline & pAkt (Ser473) & Rabbit & & Cell Signaling Technology \\
\hline & S6k1 & Rabbit & & Millipore \\
\hline & pS6k1 (Thr389) & Rabbit & & Millipore \\
\hline & eEF2 & Rabbit & & Cell Signaling Technology \\
\hline & peEF2 (T56) & Rabbit & 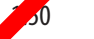 & Abcam \\
\hline & $\mathrm{PGC}-1 \alpha$ & Rabbit & $1: 50$ & Santa Cruz Biotechnology \\
\hline & Calpain I & Mouse & 1:100 & Millipore \\
\hline & Calcineurin A & adovort & 1:50 & Cell Signaling Technology \\
\hline & Cdk5 & Mouse & 1:50 & Invitrogen \\
\hline & p25 & & 1:100 & Millipore \\
\hline & $\mathrm{p} 35 / 25$ & & 1:50 & Cell Signaling Technology \\
\hline & GluT3 & & 1:50 & Santa Cruz Biotechnology \\
\hline & BACE1 & & 1:50 & Santa Cruz Biotechnology \\
\hline & hsAPP $\beta$ & Rabbit & 1:50 & $\mathrm{IBL}$ \\
\hline & NR2A & Goat & 1:50 & Santa Cruz Biotechnology \\
\hline & NR1 & Goat & 1:50 & Santa Cruz Biotechnology \\
\hline \multirow[t]{9}{*}{ Western blot } & NR2B & Rabbit & $1: 6000$ & Santa Cruz Biotechnology \\
\hline & & Rabbit & 1:1000 & Cell Signaling Technology \\
\hline & & Rabbit & 1:1000 & Cell Signaling Technology \\
\hline & & Rabbit & $1: 50$ & Cell Signaling Technology \\
\hline & & Rabbit & $1: 1000$ & Cell Signaling Technology \\
\hline & & Rabbit & $1: 6000$ & Cell Signaling Technology \\
\hline & & Rabbit & $1: 500$ & Cell Signaling Technology \\
\hline & & mouse & $1: 6000$ & Signet \\
\hline & & Rabbit & 1:50 & $\mathrm{IBL}$ \\
\hline Experiments & Secondary antibodies & & Dilution & Source \\
\hline \multirow[t]{3}{*}{ Quantitative immunostaining } & \multicolumn{2}{|c|}{$\mathrm{CF}^{\mathrm{TM}} 488$-conjugated goat anti-mouse $\lg \mathrm{G}(\mathrm{H}+\mathrm{L})$} & 1:200 & Biotium \\
\hline & \multicolumn{2}{|c|}{$\mathrm{CF}^{\mathrm{TM}} 488$-conjugated goat anti-rabbit lgG $(\mathrm{H}+\mathrm{L})$} & $1: 200$ & Biotium \\
\hline & \multicolumn{2}{|c|}{$\mathrm{CF}^{\mathrm{TM}} 488$-conjugated rabbit anti-goat lgG $(\mathrm{H}+\mathrm{L})$} & 1:200 & Biotium \\
\hline \multirow[t]{2}{*}{ Western blot } & \multirow{2}{*}{\multicolumn{2}{|c|}{$\begin{array}{l}\text { HRP-conjugated goat anti-rabbit } \lg G(\mathrm{H}+\mathrm{L}) \\
\text { HRP-conjugated goat anti-mouse } \lg \mathrm{G}(\mathrm{H}+\mathrm{L})\end{array}$}} & $1: 20000$ & ZSGB-BIO \\
\hline & & & 1:25000 & Cell Signaling Technology \\
\hline
\end{tabular}

area of interest was manually outlined and the percentage of area occupied by $\mathrm{A} \beta$ plaque in the hippocampus and frontal cortex was calculated.

\section{$A \beta 42$ and $A \beta 40$ concentrations in the CSF}

To determine the concentration of $\mathrm{A} \beta 42$ and $\mathrm{A} \beta 40$ monomers in the CSF, mice were anesthetized with chloral hydrate $(400 \mathrm{mg} / \mathrm{kg}$, i.p.) and then the CSF was manually obtained from the cisterna magna by the interruption of the atlanto-occipital membrane using recording pipettes (diameter $0.5 \mu \mathrm{m}$ ). CSF samples ( $8 \mu \mathrm{l} /$ mouse) were collected and stored at $-20^{\circ} \mathrm{C}$ until measurement was performed. The $\mathrm{A} \beta 42$ and $\mathrm{A} \beta 40$ monomers concentrations were determined using an ELISA kit (human $\mathrm{A} \beta$ [1-40] and [1-42] kits; Wako). The procedure was performed with complete adherence to the manufacturer's instructions.

Hippocampal electrical stimulation for quantitative

fluorescent immunostaining

Each group, WT, untreated $\mathrm{Tg}$, and $\mathrm{MgT}$-treated $\mathrm{Tg}(\mathrm{Tg}+\mathrm{MgT})$ mice, was divided into two subgroups: one group was used as the baseline and the other was electrically stimulated (in the hippocampus). In the baseline groups, mice were not exposed to any behavioral or electrical stimulation before they were perfused. In the electrically stimulated groups, mice were anesthetized with urethane $(2 \mathrm{~g} / \mathrm{kg}$, i.p.) and fixed in a stereotaxic apparatus (SN-2; Narishige). A stimulating electrode was placed in 
the hippocampus to stimulate the Schaffer collateral-CA1 pathway. The stimulating electrode was positioned $1.7 \mathrm{~mm}$ posterior to bregma, 1.6 $\mathrm{mm}$ lateral to midline, and $\sim 1.8 \mathrm{~mm}$ from dura. A high-frequency stimulation protocol was used to stimulate the hippocampus $(100 \mathrm{~Hz}, 50$ pulses, trains at $15 \mathrm{~s}$ intervals). Mice were perfused $2 \mathrm{~h}$ after the electric stimulation protocol was begun, as described above. However, the fixed brains were frozen and stored at $-80^{\circ} \mathrm{C}$ after the fixation procedure instead of paraffin embedding.

\section{Environmental-enrichment-based stimulation for immunostaining and Western blot analyses}

For quantitative Western blot (Figs. 3I-L, $7 D, F, G, 8$ ) and immunostaining (Fig. 9F-H) experiments, mice were exposed to environmentalenrichment-based behavioral stimulation for $24 \mathrm{~h}$ before being killed. Mice were housed individually in standard cages $\left(300 \mathrm{~cm}^{2}\right.$ floor space). The stimulus of enrichment was divided into two phases: grouping (for $21 \mathrm{~h}$ ) and physical training (for $3 \mathrm{~h}$ ). During the grouping phase, mice were group-housed in a large cage $(5-6$ mice/cage, $70 \times 60 \times 30 \mathrm{~cm})$ without any running wheels or toys. During the physical-training phase, the mice in the large cage were given running wheels, play tubes, and wood boxes.

\section{Expression/phosphorylation of signaling molecules in the hippocampus by fluorescent immunostaining}

Frozen coronal brain sections ( $5 \mu \mathrm{m}$ thick) were cut, mounted on Superfrost slides (Thermo Scientific), and left to dry overnight at room temperature. Sections were blocked, incubated with a primary antibody (Table 1), washed, and incubated with the corresponding secondary antibody (Table 1) exactly as described above. Slides were coverslipped and coded until the completion of data analysis. Hippocampal immunostained brain sections were imaged with an Olympus IX-70 confocal microscope at $10 \times$, with a water lens (numerical aperture $=0.4$ ), at a $1 \times$ zoom. Serial $z$-sectioning was performed ( $1 \mu \mathrm{m}$ thick) and the bes $z$-sections (i.e., those with the highest fluorescent intensity) were co lected and merged into a single image. The area of interest, th area of the DG, was manually traced and the mean fluor in the selected area was quantified using Image-P Only for phosphorylated CREB ( pCREB)/CREB was the sampled area of interest in the cell body $f$ t DG. Th, mean fluorescent densities after background subt action (a itrary units) in the DG were used as measure of the ley of expressionsphosphorylation of the protein in each image. Thr bra sections were imaged per mouse and the average of meap-ansi from the three images represented the readout per in vidu 1 mo An unbiased and blinded quantification protoco vas $y$ - trall quantifications.

\section{Western blot}

Frozen $\left(-80^{\circ} \mathrm{C}\right)$ hippocampal tissues were homogenized and equal amounts of proteins were resolved on polyacrylamide gel and then transferred to PVDF membranes (Millipore). Membranes were blocked and then probed with primary antibodies against NR2B (H-50, sc-9057; Santa Cruz Biotechnology), $\beta$-secretase (BACE1, D10E5), CREB, pCREB, CaMKII, phosphorylated CaMKII ( $\mathrm{pCaMKII),} \mathrm{GAPDH} \mathrm{(all}$ from Cell Signaling Technology), sAPP $\beta$ (IBL) or $\beta$-CTF (6E10, Signet; Table 1) overnight at $4^{\circ} \mathrm{C}$. Membranes were then incubated with an HRP-conjugated secondary antibody (ZSGB-BIO or Cell Signaling Technology; Table 1) at room temperature. Protein bands were detected by ECL detection reagent (RPN2232; GE Healthcare) and captured on autoradiography film (Kodak). The integrated OD was determined using Image-Pro Plus software. Standard curves were constructed to confirm that we operated within the linear range of the detection method. Codetection of GAPDH on the same membrane served as a loading control. Quantitative analysis was performed by experimenters who were unaware of the treatment and genotype of each group.

\section{In vivo and in vitro recording}

Input-output relationship in CA1 synapses in vivo. Mice were anesthetized with urethane $(2 \mathrm{~g} / \mathrm{kg}$, i.p.) and fixed in a stereotaxic apparatus $(\mathrm{SN}-2$; Narishige). Field postsynaptic potentials (fPSPs) were recorded from the stratum radiatum in CA1 after electrical stimulation of Schaffer collater- al-commissural pathway. The optimal electrode placement was determined using electrophysiological criteria as described previously (Leung, 1979). The recording electrode was positioned at $2.3 \mathrm{~mm}$ posterior to bregma, $1.75 \mathrm{~mm}$ lateral to midline, and the depth of recording electrode was $\sim 1.6 \mathrm{~mm}$ from dura. The stimulating electrode was positioned 1.7 $\mathrm{mm}$ posterior to bregma and $1.6 \mathrm{~mm}$ lateral to midline and $\sim 1.8 \mathrm{~mm}$ from dura. The positions of the recoding and stimulation electrodes were confirmed by trailing the electrodes in brain sections from representative animals. A single square pulse of voltage at low frequency $(0.066 \mathrm{~Hz}, 0.2$ ms duration) was used to evoke fPSPs and the intensity of the test stimulus was adjusted to produce $\sim 50-55 \%$ of maximum response.

Slice preparation for in vitro recordings. Acute coronal slices of hippocampus (400 $\mu \mathrm{m}$ thick) were prepared from 4-week-old male C57BL/6 mice as described previously (Wei et al., 2002). Briefly, slices were transferred and submerged in a recovery chamber containing oxygenated $\left(95 \% \mathrm{O}_{2}\right.$ and $\left.5 \% \mathrm{CO}_{2}\right)$ artificial CSF (ACSF) containing the following (in mM): $125 \mathrm{NaCl}, 2.5 \mathrm{KCl}, 2 \mathrm{CaCl}_{2}, 1.2$ or $0.8 \mathrm{MgCl}_{2}, 26$ $\mathrm{NaHCO}_{3}, 1.25 \mathrm{NaH}_{2} \mathrm{PO}_{4}$, and 25 glucose. The extracellular magnesium concentration $\left(\left[\mathrm{Mg}^{2+}\right]_{0}\right)$ varied according to the experimental conditions. Slices were incubated CSF containing either a physiological $(0.8 \mathrm{~mm})$ or high $\left(1.2 \mathrm{~m}, \mathrm{Mg}\right.$ at $32^{\circ} \mathrm{C}$ for $1 \mathrm{~h}$ and then at room temperature for $3 \mathrm{~h}$ bee recordi $\mathrm{g}$. Regardless of the preincubation conditions, the re rding $\mathrm{s}$ pe ormed under $1.2 \mathrm{~mm}\left[\mathrm{Mg}^{2+}\right]_{\mathrm{o}}$ to avoid any poten acu effec elevating $\left[\mathrm{Mg}^{2+}\right]_{0}$.

$A \beta$ and FK50 A Aration of $A \beta$ and FK506 was done as described previously snyder $1 ., 2$ 5). Briefly, A $\beta 42$ monomer ( $1 \mu \mathrm{M}, \mathrm{A} \beta$ protein fra ne, 1-42; Sis a) and/or FK506 (10 $\mu \mathrm{M}$, Sigma) were applied into the ACSN ter the $3 \mathrm{~h}$ recovery period for $1 \mathrm{~h}$ before recording

Whole-c recordings in vitro. Experiments were performed in a reding ch nber on the stage of a microscope (Eclipse FN1; Nikon) with int iferential interference contrast optics (IR1000; Dage-MTI) for - 1 alizing whole-cell patch-clamp recordings. EPSCs were recorded from CA1 pyramidal neurons using an EPC-9 amplifier with Pulse version 8.65 software (HEKA) while stimulating the Schaffer collateralcommissural pathway. A moderate constant amplitude stimulus was maintained with a Stimulus Isolator A365 (World Precision Instruments) with bipolar tungsten stimulating electrode to stimulate axonal fibers and a population of synapses. The extracellular solution also contained picrotoxin (100 $\mu \mathrm{m}$; Sigma) to block fast GABAergic inhibition. The recording pipettes $(3-5 \mathrm{M} \Omega)$ were filled with solution containing the following (in mM): 130 Cs-gluconate, $4 \mathrm{NaCl}, 0.5 \mathrm{MgCl}_{2}, 5 \mathrm{EGTA}, 10$ HEPES, $5 \mathrm{MgATP}, 0.5 \mathrm{Na}_{3} \mathrm{GTP}$, and $5 \mathrm{QX}-314$ adjusted to $\mathrm{pH} 7.3$ with $\mathrm{CsOH}$ and osmolality 290-295 with double-distilled water.

For $\mathrm{EPSC}_{\mathrm{NMDA}} / \mathrm{EPSC}_{\mathrm{AMPA}}$ experiments, after whole-cell patch clamping, neurons were voltage clamped at $-70 \mathrm{mV}$ to record the $\mathrm{EP}$ $\mathrm{SC}_{\mathrm{AMPA}}$ and then at $+50 \mathrm{mV}$ to record the $\mathrm{EPSC}_{\mathrm{NMDA}}$ (with liquid junction potential correction). EPSCs were induced by repetitive stimulations at $0.1 \mathrm{~Hz}$. The peak amplitude of EPSC $_{\mathrm{AMPA}}$ was determined at the peak of the EPSCs recorded at $-70 \mathrm{mV}$; the peak amplitude of EP$\mathrm{SC}_{\mathrm{NMDA}}$ was determined at $+50 \mathrm{mV}$ and $200 \mathrm{~ms}$ after stimulation. The ratio of the amplitudes of EPSC $_{\text {NMDAR }}$ to $\operatorname{EPSC}_{\text {AMPA }}\left(I_{\text {NMDA/AMPA }}\right)$ was calculated from the recorded data of individual neurons.

\section{Statistics}

Learning curves in the water maze task were analyzed using two-way ANOVA (treatment $\times$ trials) repeated measures. The water maze memory tests, NORT, magnesium contents in brain tissue, electron microscopy, fluorescent immunostaining, and Western blot data were analyzed using one-way ANOVA followed by Bonferroni's post hoc test. All data comparing two groups were analyzed using two-tailed unpaired $t$ test. $p<0.05$ was considered statistically significant.

\section{Results}

Elevation of brain magnesium prevents learning and memory deficits in Tg mice

We chose APPswe/PS1dE9 transgenic mice (referred to hereafter as $\mathrm{Tg}$ mice) as an animal model of $\mathrm{AD}$ that exhibits high brain amyloid deposits (Borchelt et al., 1997) and severe deficits in 
Table 2. Body weight, food/fluid intake, and locomotor activity in the open field of WT $(n=7), \operatorname{Tg}(n=6)$, and $\operatorname{Tg}+\mathrm{MgT}(n=6)$ mice and the velocity in the water maze task of WT, $\mathrm{Tg}$, and $\mathrm{Tg}+\mathrm{MgT}$ mice at age of 7 months $(n=9,13,9$, respectively) and 15 months $(n=9,7,6$, respectively)

\begin{tabular}{|c|c|c|c|c|c|c|c|}
\hline \multirow[b]{2}{*}{ Group } & \multirow[b]{2}{*}{ Body weight (g) } & \multirow[b]{2}{*}{ Food intake $(\mathrm{g} / \mathrm{d})$} & \multirow[b]{2}{*}{ Fluid intake $(\mathrm{ml} / \mathrm{d})$} & \multicolumn{2}{|c|}{ Locomotor activity in the open field } & \multicolumn{2}{|c|}{ Velocity in the water maze $(\mathrm{cm} / \mathrm{s})$} \\
\hline & & & & Velocity $(\mathrm{cm} / \mathrm{s})$ & Distance traveled (cm) & Age 7 months & Age 15 months \\
\hline WT & $42.84 \pm 3.92$ & $4.08 \pm 0.61$ & $7.16 \pm 0.26$ & $5.72 \pm 0.75$ & $3403.99 \pm 443.13$ & $11.2 \pm 1.1$ & $12.9 \pm 2.6$ \\
\hline $\mathrm{Tg}$ & $40.87 \pm 10.80$ & $3.41 \pm 1.48$ & $6.83 \pm 0.71$ & $4.34 \pm 0.48$ & $2573.52 \pm 286.99$ & $9.9 \pm 1.1$ & $11.1 \pm 1.9$ \\
\hline $\mathrm{Tg}+\mathrm{MgT}$ & $39.73 \pm 3.57$ & $3.69 \pm 0.74$ & $6.25 \pm 1.00$ & $5.03 \pm 0.32$ & $2954.00 \pm 159.68$ & $10.8 \pm 1.5$ & $11.8 \pm 2.4$ \\
\hline
\end{tabular}

One-way ANOVA revealed no significant differences among the three groups of mice. Data are presented as mean \pm SD.

spatial memory at 6-7 months of age (Reiserer et al., 2007; Ding et al., 2008; Bernardo et al., 2009). In our previous study in rats, the effective dosage for memory enhancement by $\mathrm{MgT}$ was 50 $\mathrm{mg} / \mathrm{kg} / \mathrm{d}$ of elemental Mg (Slutsky et al., 2010). The equivalent elemental magnesium dose in mice is $75 \mathrm{mg} / \mathrm{kg} / \mathrm{d}(910 \mathrm{mg} / \mathrm{kg} / \mathrm{d}$ of MgT; Reagan-Shaw et al., 2008). This dose was effective at elevating the $\mathrm{Mg}^{2+}$ concentration in plasma and RBCs (Fig. $1 G, H)$. Interestingly, we found that the $\mathrm{Mg}^{2+}$ concentration in the plasma of untreated $\mathrm{Tg}$ mice was significantly lower than that of WT mice (Fig. 1G), which is consistent with previous studies showing reductions in the $\mathrm{Mg}^{2+}$ concentration in the serum of AD patients (Barbagallo et al., 2011).

We investigated whether elevating brain magnesium could prevent learning and memory deficits in Tg mice. MgT treatment started at 6 months of age. After 1 month of MgT treatment, we assessed spatial learning and memory abilities using the water maze task. Untreated Tg mice exhibited unequivocal learning deficits in this task at 7 months of age. In contrast, $\mathrm{Tg}+\mathrm{MgT}$ mice performed quite similarly to WT mice (Fig. 1A). When we did probe test $24 \mathrm{~h}$ after the last training trial, untreated $\mathrm{Tg} \mathrm{mi}$ showed no preference toward the target quadrant, indicating sig nificant memory impairment, whereas $\mathrm{Tg}+\mathrm{MgT}$ aice performed as well as WT (Fig. 1B).

The improvement of cognitive functions cer 1) onth of treatment with $\mathrm{MgT}$ is interesting. Howeve, $\mathrm{h}$ thera point of view, efficacy of MgT on cogr tive fun tion over a longer time course is more importan To determin whether MgT remained effective over a long orm reatment, the same groups of mice were retested at nd mo hs of age (after 9 and 16 months of $\mathrm{MgT}$ eatn ent, pectively). At 15 months, learning and memo a mossesed using the same water maze task (mo fied protocol, see Materials and Methods). Tg mice completer/lost their ability to locate the hidden platform, whereas $\mathrm{Tg}+\mathrm{MgT}$ and $\mathrm{WT}$ mice could readily locate it (Fig. $1 C$ ). In the probe test, $\mathrm{Tg}+\mathrm{MgT}$ mice, similar to WT, spent significantly more time in the target quadrant compared with other quadrants, whereas untreated Tg mice swam randomly (Fig. 1D). We did not observe significant differences in the velocity in the water maze among the three groups of mice at the ages of 7 and 15 months (Table 2), indicating that the differences in latencies/time in quadrant among the groups were not because the untreated $\mathrm{Tg}$ mice swam slower than the other mice.

At 22 months, we assessed STM and LTM using a modified version of the standard NORT. The NORT was selected to avoid repeating the water maze task for the third time and because the mice were too weak to perform the water maze task at the age of 22 months. During the STM test (10 min retention interval), Tg mice did not show any preference toward the novel object. In contrast, WT and Tg+MgT mice spent significantly more time exploring the novel object (Fig. 1E, left). During the LTM test (24 $\mathrm{h}$ retention interval), only WT and $\mathrm{Tg}+\mathrm{MgT}$ mice exhibited clear preference toward the novel object (Fig. 1E, right). Therefore,
MgT treatment remained effective after long-term (up to 16 months) treatment.

To confirm that MgT treatment was associated with elevating brain magnesium, we quantified the magnesium contents (total magnesium in tissue) in brain and in other organs in the behaviorally tested mice mentioned above (perfused at age of 23 months). MgT treatment selectively elevated $\mathrm{Mg}^{2+}$ content in the brain and kidneys (Fio $1 F$ ) of Tg mice. Interestingly, in untreated $\mathrm{Tg}$ mice, b an m osium levels were positively correlated with cogn ive fund on; the lower the brain magnesium, the poo r the nem function in the NORT task (Pearson's te,$r^{2}>0.7>P=0.02$; Fig. $1 I$ ). We did not observe sis ifin side fects over the entire time course of MgT tre ment ( $\mathrm{b} / 2)$.

\section{El mion of b in magnesium prevents synapse loss in g mice}

study he cellular mechanisms underlying the prevention of mor deficits in Tg mice by MgT, we examined effects of this atment on synapse density. The brains of the same mice used in the above-described behavioral experiments (Fig. 1) were subjected to histological analysis. First, we quantified synapse density in the hippocampus, a brain region critical for memory function. Tg mice had a significantly lower number of synapses (by $\sim 25.3 \%$ ) compared with WT; this synapse loss was prevented by MgT treatment (Fig. 2A; for ANOVA analysis, see Table 3). Next, we determined the total presynaptic terminal density using the synaptic vesicle marker synaptophysin, in the hippocampal DG. In $\mathrm{Tg}$ mice, there were significantly fewer synaptic puncta $(\sim 32.5 \%)$ than in WT mice. MgT treatment prevented this reduction in $\mathrm{Tg}$ mice (Fig. 2B, Table 3).

Next, we examined the effects of MgT treatment on different types of neurotransmitter terminals using VGluT1 to label glutamatergic terminals, GAD65 to label GABAergic terminals, and vAChT to label acetylcholinergic terminals. Tg mice had significantly lower immunostained puncta density for VGluT1 (by $\sim 42.8 \%$; Fig. 2C), GAD65 ( 33.3\%; Fig. $2 D$ ), and VAChT ( $\sim 58 \%$; Fig. $2 E$ ) than WT. MgT treatment prevented the loss in glutamatergic and GABAergic terminals and, to a lesser extent, in acetylcholinergic terminals (Fig. 2C-E, Table 3). To determine the functional consequences of synapse density reduction on glutamatergic synaptic transmission, we compared the input-output relationship of hippocampal CA1 synapses in vivo in a separate group of mice ( 15 months old, MgT treatment for 9 months). The amplitude of fPSPs for a given stimulus intensity was significantly lower in $\mathrm{Tg}$ mice compared with $\mathrm{WT}$, whereas $\mathrm{Tg}+\mathrm{MgT}$ mice had a similar input-output relationship as WT (Fig. $2 F$ ). Therefore, $\mathrm{MgT}$ treatment was also effective at preventing reductions in glutamatergic synaptic transmission.

Finally, we plotted the relationship between synapse density and STM (quantified by the recognition index during the NORT task) in Tg mice. Memory performance was correlated with the density of synaptophysin puncta $\left(r^{2}=0.78, p=0.02\right.$; Fig. $\left.2 G\right)$, 


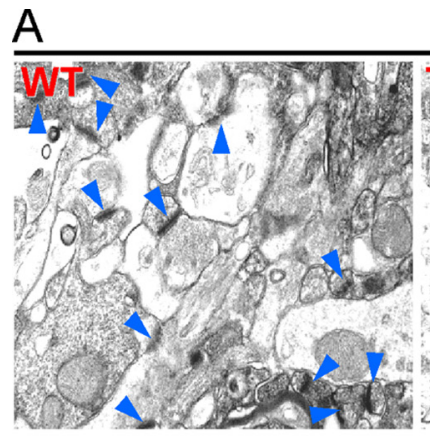

\section{DG OML}

B

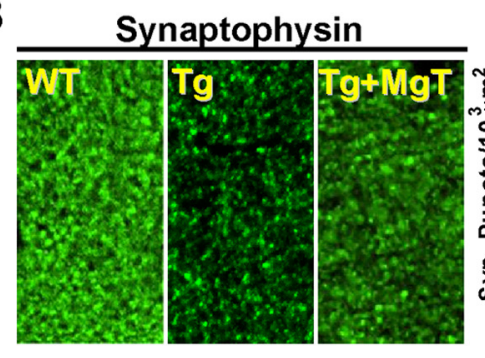

$\mathrm{D}$

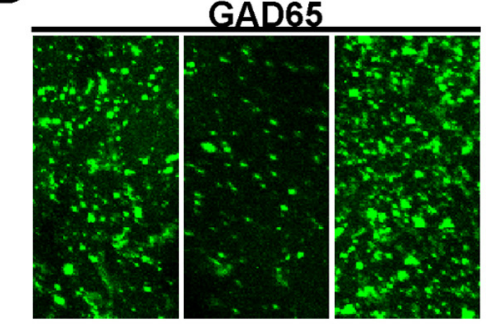

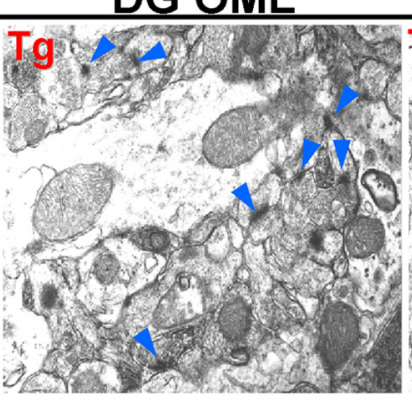

C

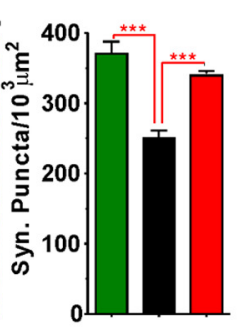

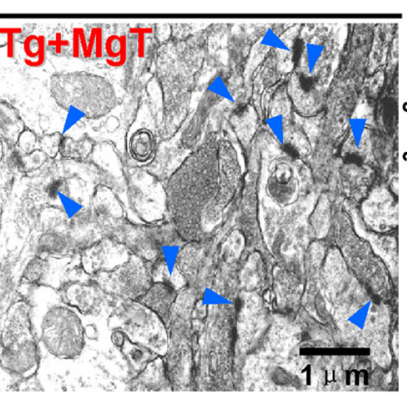

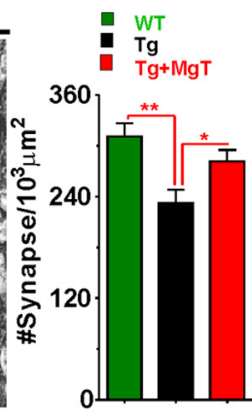

VGluT1

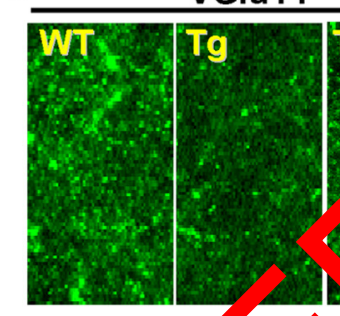

$\mathrm{E}$
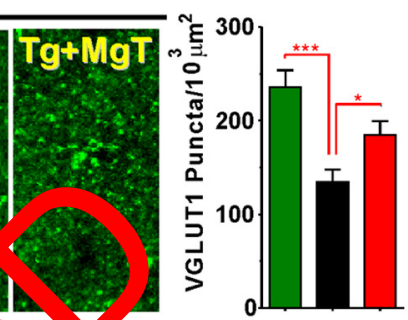
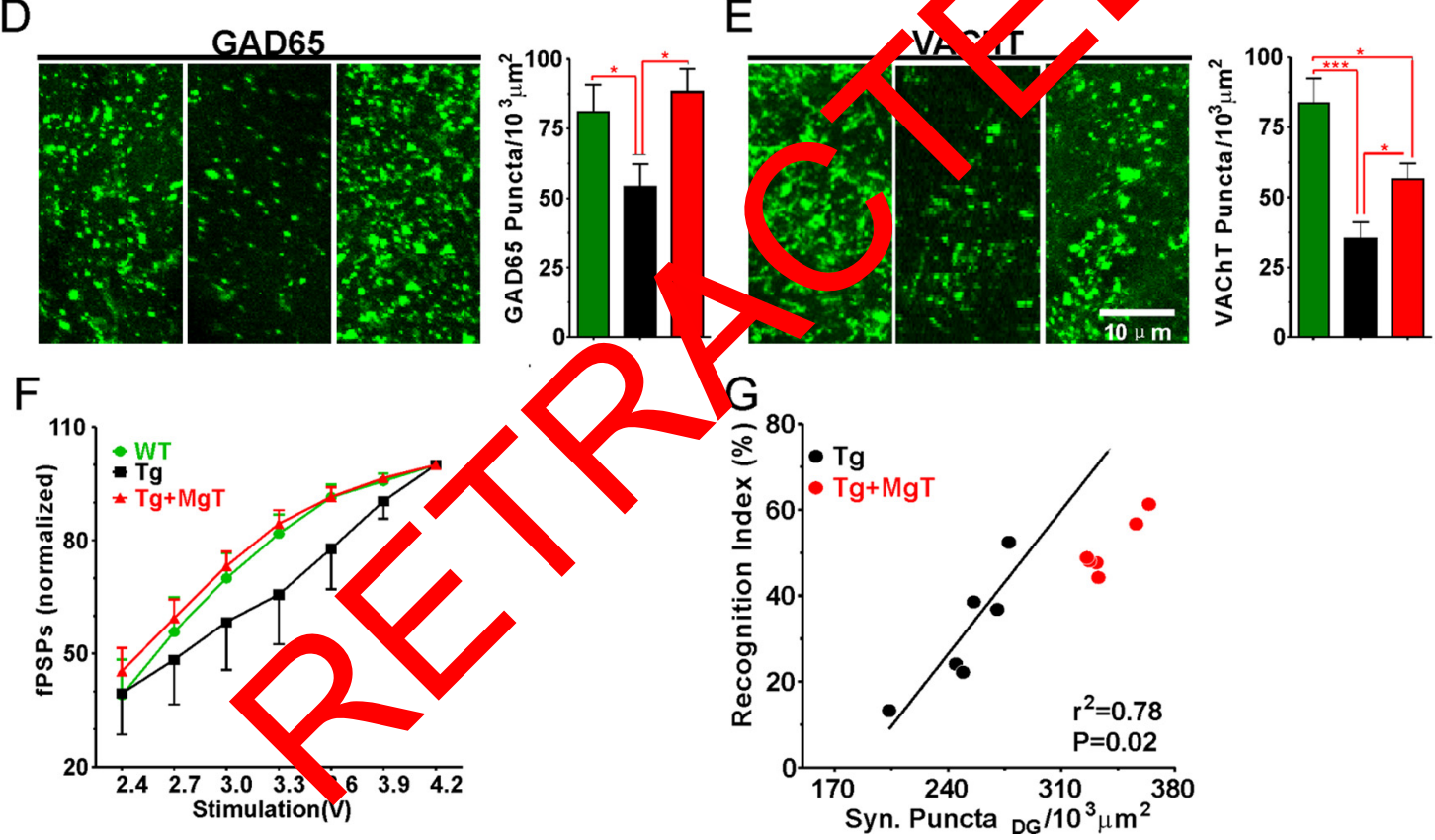

Figure 2. Prevention by MgT treatment of synapse loss in Tg mice. $A$, Left, Electron microscopic images showing structural synapses (blue arrows) in hippocampal outer molecular layer of $D G$ (DG-OML). Right, Estimated synaptic density (WT, $n=6 ; \mathrm{Tg}, n=6 ; \mathrm{Tg}+\mathrm{MgT}, n=5$ ). B, Left, Immunostaining of synaptophysin-positive terminals (Syn Puncta) in DG-OML. Right, Quantitative analysis of Syn Puncta ( $n=6 /$ group). $\boldsymbol{C}-\boldsymbol{E}$, Same as in $\boldsymbol{B}$ and from same groups of mice; however, puncta represent glutamatergic (VGluT1, C), GABAergic (GAD65, D), and acetylcholinergic terminals (vAChT, $\boldsymbol{E}$ ). ANOVAs (Table 3) were followed by Bonferroni's post hoc test. $\boldsymbol{F}$, Input-output (normalized) relationship of hippocampal CA1 synapses in vivo ( $n=6 /$ group). fPSPs were normalized by the maximum amplitude of fPSPs. Two-way ANOVA revealed significant effects of treatment $(p<0.05)$ and stimulus $(p<0.0001)$. G. Correlation between the density of Syn Puncta and STM in $\operatorname{Tg}$ mice (23 months old). $\mathrm{Tg}+\mathrm{MgT}$ ( 23 months old treated for 17 months) data are displayed, but were not included in the regression analysis (Pearson's test). Error bars show SEM. ${ }^{*} p<0.05 ;{ }^{* *} p<$ $0.01 ;{ }^{* * *} p<0.001$.

suggesting that synapse loss might be one of primary factors underlying memory deficits in $\mathrm{Tg}$ mice.

\section{Impairment of NMDAR signaling in Tg mice}

Having demonstrated that Tg mice have significant reductions in structural synapse density and glutamatergic synaptic transmission, we next evaluated whether the remaining synapses retain the plasticity essential for memory encoding. First, we examined the NMDAR signaling pathway in the hippocampal DG. In a new group of mice, $\mathrm{MgT}$ treatment was initiated at 6 months of age and continued for 9 months, at which point the mice were per- fused (at the age of 15 months). The expression of NR2B and pNR2B (the membrane-surface-stabilized portion; Salter and Kalia, 2004) was lower in Tg mice (by $\sim 18.5 \%$ and $\sim 23 \%$, respectively) than in WT (Fig. $3 A, B$, left), whereas the NR2A and NR1 subunits did not differ (data not shown). Signaling molecules downstream of NMDAR, such as those for calmodulin expression, CaMKII phosphorylation, and ERK1/2 phosphorylation, were also lower in Tg mice compared with WT (by $\sim 26.8$, $\sim 59.2 \%$, and $\sim 66.7 \%$; respectively; Fig. $3 C, D, F$, left). CREB phosphorylation appeared to be lower ( $\sim 26.8 \%$; Fig. $3 E$, left), but this was not statistically significant. Surprisingly, BDNF ex- 
Table 3. One-way ANOVA analysis of electron microscopy, immunostaining, and Western blot data

\begin{tabular}{|c|c|c|c|c|c|c|}
\hline \multirow[b]{2}{*}{ Value protein } & \multicolumn{3}{|l|}{ Basal } & \multicolumn{3}{|l|}{ Stimulation } \\
\hline & Fvalue & $p$ value & Figure & Fvalue & $p$ value & Figure \\
\hline Structural synapses & $F_{(2,14)}=7.243$ & 0.0069 & $2 A$ & NA & NA & NA \\
\hline Synaptophysin & $F_{(2,15)}=26.21$ & $<0.0001$ & $2 B$ & NA & NA & NA \\
\hline GAD65 & $F_{(2,15)}=4.130$ & 0.0373 & $2 D$ & NA & NA & NA \\
\hline VAChT & $F_{(2,15)}=12.04$ & 0.0008 & $2 E$ & NA & NA & NA \\
\hline NR2B & $F_{(2,15)}=9.891$ & 0.0018 & $3 A$ & $F_{(2,15)}=5.379$ & 0.0173 & $3 A$ \\
\hline Calmodulin & $F_{(2,15)}=5.288$ & 0.0183 & $3 D$ & $F_{(2,15)}=7.360$ & 0.0059 & $3 D$ \\
\hline pCreb/Creb & $F_{(2,15)}=3.638$ & 0.0516 & $3 E$ & $F_{(2,15)}=14.89$ & 0.0003 & $3 E$ \\
\hline pErk $_{1 / 2} /$ Erk $_{1 / 2}$ & $F_{(2,15)}=8.784$ & 0.0030 & $3 F$ & $F_{(2,15)}=6.927$ & 0.0074 & $3 F$ \\
\hline BDNF & $F_{(2,15)}=1.338$ & 0.2921 & $3 G$ & $F_{(2,15)}=25.17$ & $<0.0001$ & $3 G$ \\
\hline pTrkB/TrkB & $F_{(2,15)}=3.660$ & 0.0508 & $3 H$ & $F_{(2,15)}=11.38$ & 0.0010 & $3 H$ \\
\hline NR2B/GAPDH & $F_{(2,12)}=1.026$ & 0.3877 & 3」 & $F_{(2,14)}=55.26$ & $<0.0001$ & 31 \\
\hline pS6k1/S6k1 & $F_{(2,15)}=0.349$ & 0.7108 & $4 C$ & 7828 & 0.0047 & $4 C$ \\
\hline peEF2/eEF2 & $F_{(2,15)}=2.125$ & 0.154 & $4 D$ & & 0.0218 & $4 D$ \\
\hline $\mathrm{PGC}-1 \alpha$ & $F_{(2,15)}=6.795$ & 0.0079 & $4 E$ & & 0.0064 & $4 E$ \\
\hline Calpain I & $F_{(2,15)}=11.54$ & 0.0009 & $5 A$ & & 0.0032 & $5 A$ \\
\hline Calcineurin & $F_{(2,15)}=3.778$ & 0.0469 & $5 B$ & & 0.0217 & $5 B$ \\
\hline CDK5 & $F_{(2,15)}=3.676$ & 0.0502 & $5 C$ & -7.706 & 0.0050 & $5 C$ \\
\hline BACE1 & $F_{(2,15)}=5.989$ & 0.0122 & $7 C$ & $F_{(2,15)}=4.552$ & 0.0285 & $7 C$ \\
\hline BACE1/GAPDH & $F_{(2,12)}=11.30$ & 0.0017 & & $F_{(2,14)}=62.37$ & $<0.0001$ & $7 D$ \\
\hline NR2B & $\mathrm{NA}$ & NA & & $F_{(2,16)}=9.705$ & 0.0017 & $9 F$ \\
\hline BDNF & NA & NA & & $F_{(2,16)}=5.577$ & 0.0145 & $9 G$ \\
\hline Synaptophysin & NA & NA & & $F_{(2,16)}=20.15$ & $<0.0001$ & $9 H$ \\
\hline
\end{tabular}

NA indicates not applicable.

pression and the phosphorylation of its receptor, $\mathrm{kBB}$ mice were not lower than in WT mice (Fig. $3, H$, lo under basal conditions.

During learning and memory process , corre ed synaptic inputs activate NMDARs, leading to ilvation of downstream signaling molecules and an increase in the pression of proteins necessary for synaptic remodelin ar et a 2000). We thus evaluated NMDAR signaling noled les $\mathrm{h}, \mathrm{G}$ after electrical stimulation in vivo. A parallel ov onme was housed, treated, and handled under exactly the $\mathrm{s}$ ne conditions as those mentioned above. However, $2 \mathrm{~h}$ beforeperfusion, these mice were subjected to in vivo hippocampal electrical high-frequency stimulation using an L-LTP induction protocol $(100 \mathrm{~Hz}, 50$ pulse, 4 trains at $15 \mathrm{~s}$ interval; Ren et al., 2011), Immunostaining of this group of mice was performed simultaneously with the previously described groups to allow quantitative comparison of signaling pathways under basal and stimulated conditions. After electrical stimulation, the expression/phosphorylation levels of the NMDAR and its downstream signaling molecules increased significantly in WT mice (Fig. $3 A-E, G, H$, right). In Tg mice, although the amounts of NR2B (Fig. 3A, right), pNR2B (Fig. 3B, right), pCaMKII (Fig. 3C, right), and calmodulin (Fig. 3D, right) increased slightly, their levels remained significantly lower than in WT mice. Most importantly, electrical stimulation significantly increased the levels of pCREB ( $\sim 34 \%$; Fig. $3 E$, right), BDNF ( $\sim 100 \%$; Fig. $3 G$, right), and pTrkB ( $79 \%$; Fig. $3 H$, right) in WT mice, whereas no increase was detected in Tg mice. Therefore, dysfunction of APP metabolism not only triggered synapse loss and reduction of synaptic transmission, but also impaired NMDAR signaling activated by correlated synaptic inputs, resulting in loss of the plasticity in the remaining synapses.
The expression/activation pattern of NMDAR signaling in $\mathrm{Tg}+\mathrm{MgT}$ mice was almost identical to WT in both basal and stimulated conditions. Therefore, $\mathrm{MgT}$ treatment might protect the NMDAR signaling necessary for synaptic plasticity after neuronal activity.

To confirm the immunostaining observations, we prepared new groups of mice (killed at age of 18 months after MgT treatment was given for 12 months) and compared the expression/ phosphorylation of NMDAR signaling key proteins using quantitative Western blotting. Mice from each group were divided into two groups: half were killed under home-cage conditions (basal) and the other half were killed after $24 \mathrm{~h}$ of environmental-enrichment-based stimulation. The environmental-enrichment-based stimulus was chosen because it will evoke physiologic neuronal inputs compared with the electrical stimulation protocol used above. Environmental stimulation was effective in inducing activation of NMDAR signaling pathway in $\mathrm{WT}$, but not in Tg mice. Again, MgT treatment rescued these deficits (Fig. 3I-L).

\section{Impairment of protein synthesis and energy pathways in Tg mice}

Activity-dependent protein synthesis is essential for synaptic remodeling and memory consolidation (Costa-Mattioli et al., 2009). Therefore, we investigated the expression/phosphorylation levels of signaling molecules involved in controlling activitydependent protein synthesis in hippocampal DG. Under basal conditions, the expression of total insulin receptor substrate-1 (IRS-1) and the phosphorylation level of the downstream kinases Akt and S6K1 were similar among the three groups (Fig. $4 A-C$, left). Hippocampal electrical stimulation induced increases in 
total IRS-1 protein expression $(\sim 59 \%)$, pAkt $(\sim 71 \%)$, and pS6K1 $(\sim 38 \%)$ in WT (Fig. $4 A-C$, right), but not in $\mathrm{Tg}$ mice. Furthermore, the eukaryotic elongation factor-2 (eEF2), which is critical for controlling local protein synthesis in dendrites (Verpelli et al., 2010), was more inactivated in Tg mice under basal and stimulated conditions (by $\sim 34 \%$ and $41 \%$ of WT, respectively; Fig. $4 D$ ). Therefore, whereas the protein synthesis pathway appeared normal in Tg mice under basal conditions, the activity-dependent protein synthesis was significantly impaired. MgT treatment in $\mathrm{Tg}$ mice restored the expression/activation pattern of these signaling molecules back to that in WT mice (Fig. 4A-D).

In $\mathrm{AD}$ patients, reductions in cognitive functions are correlated with reductions in energy utilization in the brain (Minoshima et al., 1997). We studied the expression of the transcription factor PGC- $1 \alpha$, which is considered the master regulator of energy supply within cells. We found a significant reduction in the expression of PGC- $1 \alpha$ in Tg mice in both basal and stimulated conditions, whereas MgT prevented such reductions in treated Tg mice (Fig. 4E).

\section{Overactivation of $\mathrm{Ca}^{2+}$-activated} signaling molecules in $\mathrm{Tg}$ mice To explore the possible molecular mechanisms underlying the impairment in NMDAR signaling and synapse loss, we determined the expression of calpain, cineurin, and Cdk5. These molecules considered "negative regulators" th NMDAR signaling pathway ar are ften referred to as $\mathrm{Ca}^{2+}$-depender ne roum generative molecules (Simpkin et al., 2003; Snyder et al., 2005; Hawasli t al., 2007). Under basal conditions, the expression levels of calpain, calcineurin, and $\mathrm{Cdk} 5$ were significantly higher in $\mathrm{Tg}$ mice than in WT (by $\sim 27 \%, \sim 33 \%$, and $\sim 19 \%$, respectively; Fig. 5A-C, left). Unexpectedly, after electrical stimulation, the expression of calpain, calcineurin, and Cdk5 in Tg mice increased such that the difference from WT mice became even greater (by $\sim 68 \%, \sim 99.5 \%$, and $\sim 50 \%$; respectively; Fig. $5 A-C$, right). MgT treatment in Tg mice prevented the overexpression of these molecules under both basal and stimulated conditions. Therefore, elevation of brain magnesium might counteract the impairment of the NMDAR signaling pathway induced by APP toxic metabolites by reducing the expression/activity of calpain, calcineurin, and Cdk5.

To provide an overview of all investigated signaling pathways that were impaired in $\mathrm{Tg}$ mice and restored by MgT treatment, the expression/phosphorylation levels of the signaling molecules from individual mice were displayed (Fig. 5D). This display re- $\begin{array}{lllll}\text { Stim } & \text { WT } & \mathrm{Tg} & \mathrm{Tg}+\mathrm{MgT} & \text { Basal }\end{array}$

A
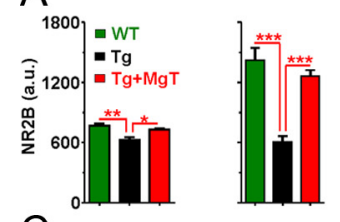

NR2B

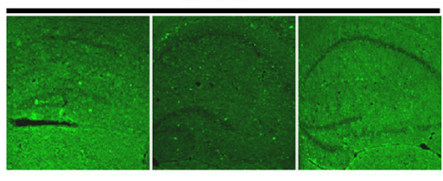

B

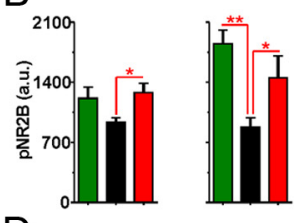

D
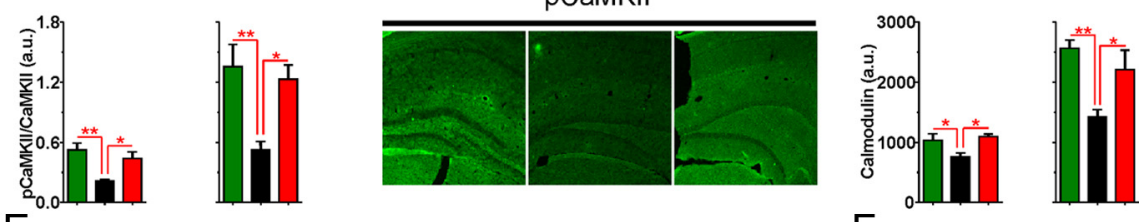

F
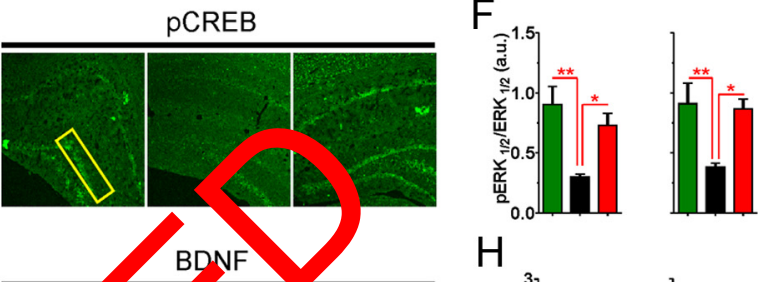

$\mathrm{H}$

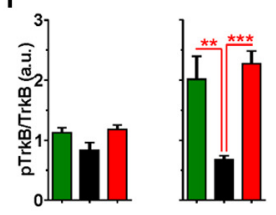

$\mathrm{K}$

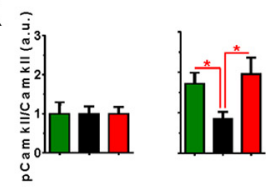

figure3. Prevention by MgT treatment of impairment in NMDAR signaling pathway in Tg mice. $\boldsymbol{A}$, Left, Quantitative analysis of NR? expression in DG of WT, $\mathrm{Tg}$, and $\mathrm{Tg}+\mathrm{MgT}$ mice $(n=6 /$ group) obtained by immunostaining (arbitrary units, a.u.). Mice were iffused under basal conditions without electrical stimulation. Middle, Quantitative analysis of NR2B expression in DG of WT, Tg, and $\mathrm{Tg}+\mathrm{MgT}$ mice ( $n=6$ /group) obtained by immunostaining after in vivo hippocampal electrical stimulation (Stim) $2 \mathrm{~h}$ before perfusion. Right, Representative fluorescent images of NR2B expression in the hippocampus after electrical stimulation. B, Same as A but quantifying phosphorylated NR2B (pNR2B). C, Phosphorylated CaMKII (pCaMKII)/CaMKII ratio. D, Calmodulin expression. $\boldsymbol{E}$, Phosphorylated CREB (pCREB)/CREB ratio (in cell body region only: yellow box). $\boldsymbol{F}$, Phosphorylated ERK1/2 (pERK1/2)/ERK1/2 ratio. G expression. $\boldsymbol{H}$, Phosphorylated TrkB (pTrkB)/TrkB ratio. I, Representative Western blots showing the expression levels of NR2B, pCaMKII, CaMKII, pCREB, and CREB in the hippocampus of mice killed either after home-cage conditions (basal) or after $24 \mathrm{~h}$ of environmental-enrichment-based behavioral stimulation (Stim). GAPDH expression served as loading control. J, Left, Quantialysis of NR2B expression in the hippocampus of WT, $\mathrm{Tg}$, and $\mathrm{Tg}+\mathrm{MgT}$ mice ( $n=5 /$ group) obtained by Western blot (arbitrary units, a.u.). Mice were killed under basal conditions without behavioral stimulation. Right, Quantitative analysis of NR2B expression the hippocampus of WT $(n=6), \operatorname{Tg}(n=6)$, and $\mathrm{Tg}+\mathrm{MgT}$ mice $(n=5)$ obtained by Western blot after behavioral stimulation. $\boldsymbol{K}$, $\boldsymbol{L}$, Same as $\boldsymbol{J}$ but quantifying pCaMKII/CaMKII ratio $(\boldsymbol{K})$ and pCREB/CREB ratio from hippocampal homogenates $(\boldsymbol{L})$. ANOVAs (Table 3) were followed by Bonferroni's post hoc test. Error bars show SEM. ${ }^{*} p<0.05$; ${ }^{* *} p<0.01$; ${ }^{* * *} p<0.001$.

veals that the downregulation of NMDAR signaling, activitydependent protein synthesis, and energy signaling and the upregulation of $\mathrm{Ca}^{2+}$-dependent neurodegenerative signaling after electrical stimulation in Tg mice are the major impaired signaling pathways (Fig. 5D, blue frames; for detailed one-way ANOVA statistical results of all studied proteins, see Table 3 ).

Prevention of exogenous A $\beta$ 42-induced downregulation of NMDAR synaptic transmission by elevation of $\left[\mathrm{Mg}^{2+}\right]_{\mathrm{o}}$ It is clear that MgT treatment not only prevented synapse loss in Tg mice, but also restored the functionality of NMDAR signaling 


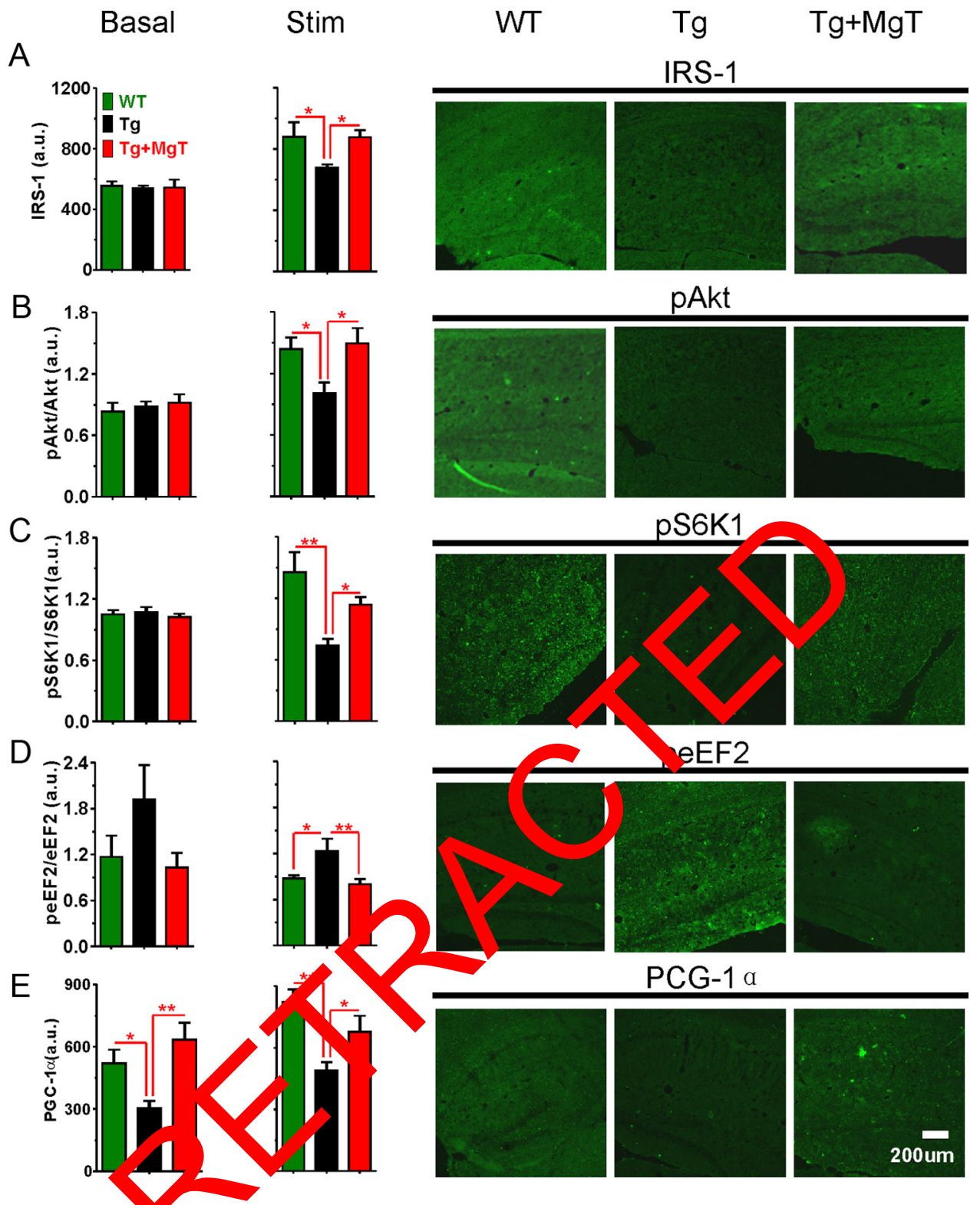

Figure 4. Prevention by MgT treatment of in, irment in activity-dependent protein synthesis and energy pathways in $\mathrm{Tg}$ mice. A, Left, Quantitative analysis of IRS-1 expression in DG of WT, Tg, and $\mathrm{Tg}+\mathrm{MgT}$ mice $(n=6 /$ group), obtained by im nostaining (arbitrary units, a.u.). Mice were perfused under basal conditions without behavioral or electrical stimulation. Middle, Expression of IRS-1 in the DG of WT, $\mathrm{Tg}$, and Tg + MgT mice ( $n=6 /$ group) obtained by immunostaining after in vivo hippocampal electrical stimulation $2 \mathrm{~h}$ before perfusion. Right, Representative fluorescent images of IRS-1 expression in the hippocampus after electrical stimulation. B, Same as $\boldsymbol{A}$ but phosphorylated Akt (pAkt)/Akt ratio. C, Phosphorylated S6K1 (pS6K1)/S6K1 ratio. D, Phosphorylated eEF2 (peEF2)/eEF2 ratio. E, PGC-1 $\alpha$ expression. ANOVAs (Table 3) were followed by Bonferroni's post hoc test. Error bars show SEM. ${ }^{*} p<0.05{ }^{* * *} p<0.01$.

in the remaining synapses. Because NMDARs are essential for synaptic plasticity and memory functions, we conducted the following experiments to explore mechanistically how elevation of $\mathrm{Mg}^{2+}$ can protect NMDARs from $\mathrm{A} \beta$-induced downregulation.

First, we studied the molecular mechanisms underlying impairment of NMDARs by $\mathrm{A} \beta$. The $\mathrm{EPSC}_{\mathrm{NMDA}} / \mathrm{EPSC}_{\mathrm{AMPA}}$ between CA3-CA1 synaptic connections (Shaffer collaterals) was recorded in hippocampal slices using whole-cell patch-clamp recordings from CA1 pyramidal neurons while stimulating Shaffer collaterals at low frequency $(0.03 \mathrm{~Hz})$. Exogenous application of $\mathrm{A} \beta$ ( $1 \mu \mathrm{M}$ for $1 \mathrm{~h}$ at room temperature) significantly reduced $I_{\mathrm{NMDA}}$ (by $\sim 48 \%$ ), when brain slices were bathed under physiological $\left[\mathrm{Mg}^{2+}\right]_{\mathrm{o}}\left(0.8 \mathrm{mM}\right.$, referred to as $0.8-\left[\mathrm{Mg}^{2+}\right]_{\mathrm{o}}$ slices; Fig. $6 B)$. A previous study suggested that downregulation of NMDARs by exogenous $A \beta$ is likely mediated by overactivation of calcineurin (Snyder et al., 2005). We confirmed those obser- vations and found that inhibition of calcineurin (FK506, $10 \mu \mathrm{M}$ for $1 \mathrm{~h}$ ) was effective at preventing downregulation of NMDARs by $\mathrm{A} \beta$ in hippocampal slices (Fig. $6 B$ ). Therefore, calcineurin might be the molecular target mediating the $\mathrm{A} \beta$-induced downregulation of NMDARs.

Next, we investigated whether calcineurin is also involved in the molecular mechanism underlying the upregulation of NMDARs by elevation of $\left[\mathrm{Mg}^{2+}\right]_{0}$ (Slutsky et al., 2004; Slutsky et al., 2010). As expected, elevation of $\left[\mathrm{Mg}^{2+}\right]_{\mathrm{o}}$ (to $1.2 \mathrm{~mm}, 1.2-$ $\left[\mathrm{Mg}^{2+}\right]_{\mathrm{o}}$ slices), increased $I_{\mathrm{NMDA}}$ (by $\sim 53 \%$, percentage of 0.8 $\left[\mathrm{Mg}^{2+}\right]_{0}$ slices; Fig. $\left.6 \mathrm{C}\right)$. Interestingly, in the presence of the calcineurin inhibitor, $I_{\mathrm{NMDA}}$ increased in $0.8-\left[\mathrm{Mg}^{2+}\right]_{\mathrm{o}}$ (Fig. $6 \mathrm{C}$ ), whereas $I_{\mathrm{NMDA}}$ in $1.2-\left[\mathrm{Mg}^{2+}\right]_{\mathrm{o}}$ remained the same such that the amplitudes of $I_{\mathrm{NMDA}}$ under $0.8-\left[\mathrm{Mg}^{2+}\right]_{\mathrm{o}}$ and $1.2-\left[\mathrm{Mg}^{2+}\right]_{\mathrm{o}}$ slices were almost identical (Fig. $6 \mathrm{C}$ ). Those data imply that elevation of $\left[\mathrm{Mg}^{2+}\right]_{\mathrm{o}}$ might upregulate $I_{\mathrm{NMDA}}$ by inhibiting calcineurin 


$$
\text { A }
$$

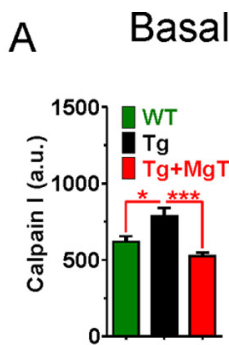

Stim

WT $\operatorname{Tg}$ $\mathrm{Tg}+\mathrm{MgT}$
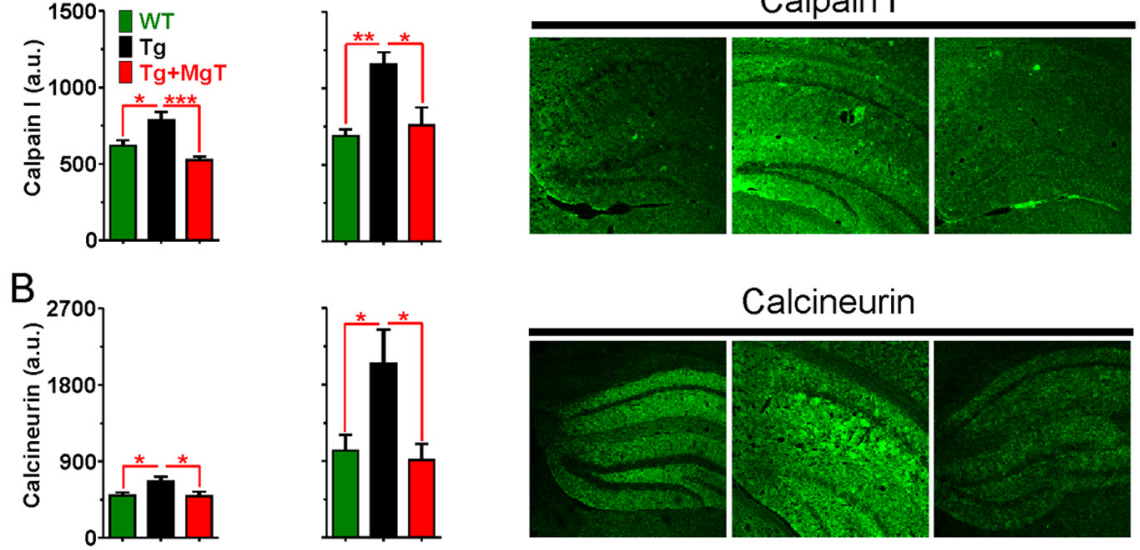

Calpain I
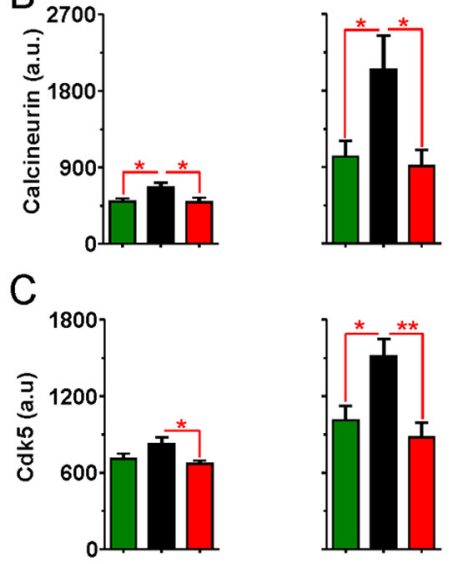

Calcineurin
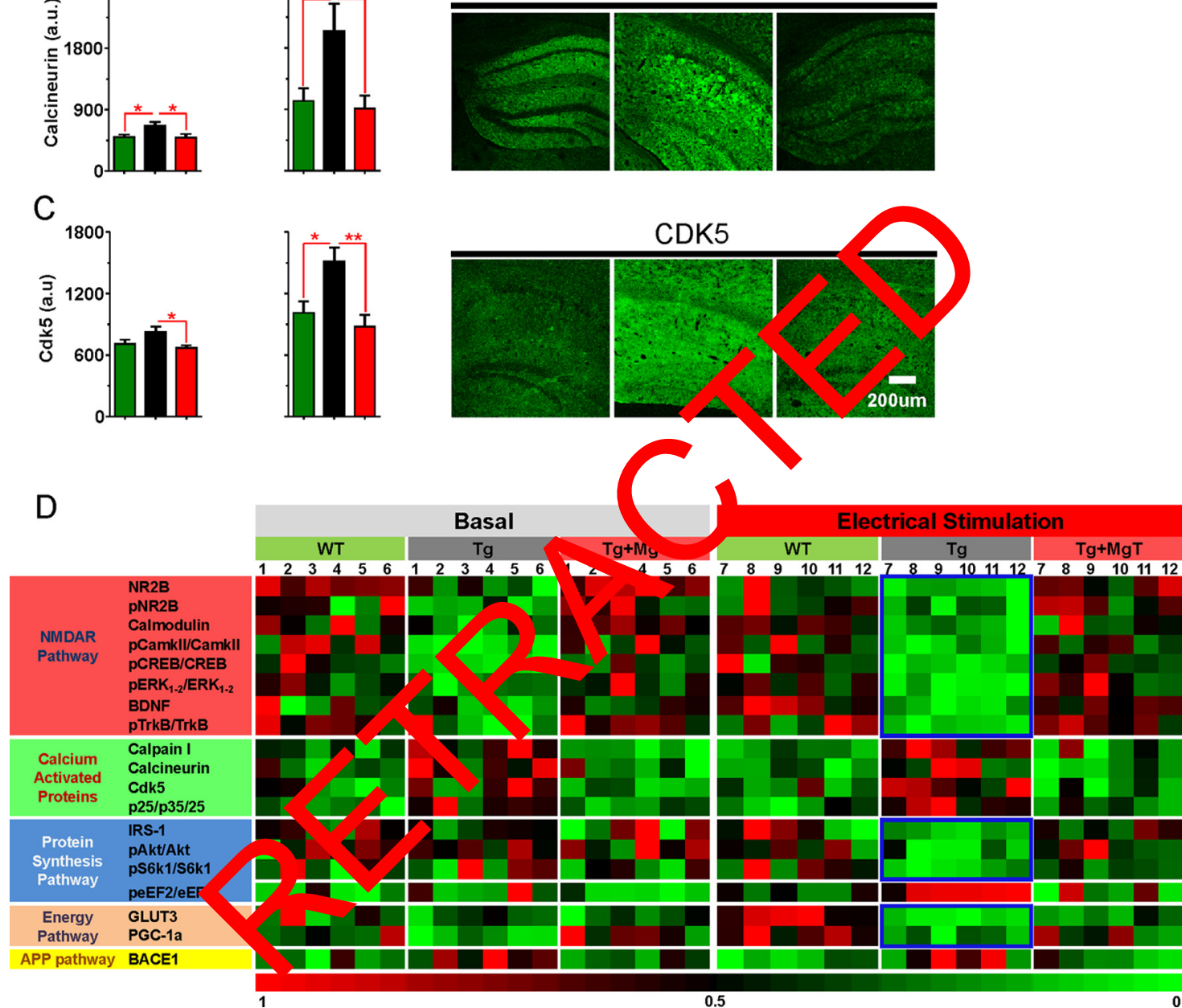

Figure 5. Prevention by MgT treatment of overexpression of $\mathrm{Ca}^{2+}$-activated neurodegenerative signaling molecules in $\mathrm{Tg}$ mice. $A$, Left, Quantitative analysis of calpain I expression in DG of WT, $\mathrm{Tg}$, and $\mathrm{Tg}+\mathrm{MgT}$ mice ( $n=6 / \mathrm{group}$ ) obtained by immunostaining (arbitrary units, a.u.). Mice were perfused under basal conditions without behavioral or electrical stimulation. Middle, Quantitative analysis of calpain I expression in DG of WT, $\mathrm{Tg}$, and $\mathrm{Tg}+\mathrm{MgT}$ mice $(n=6 / \mathrm{group})$ obtained by immunostaining after in vivo hippocampal electrical stimulation (Stim) $2 \mathrm{~h}$ before perfusion. Right, Representative fluorescent images of calpain I expression in the hippocampus after electrical stimulation. B, Calcineurin expression. C, Cdk5 expression. ANOVAs (Table 3) were followed by Bonferroni's post hoc test. Error bars show SEM. ${ }^{*} p<0.05 ;{ }^{* *} p<0.01 ;{ }^{* * *} p<0.001$. D. Cluster display summarizing the expression and/or phosphorylation level of all investigated signaling molecules under basal conditions (left) and after in vivo hippocampal electrical stimulation (right). Columns represent data from individual mice. Color intensity corresponds to the expression/phosphorylation level.

signaling. If both $\mathrm{A} \beta$ and $\left[\mathrm{Mg}^{2+}\right]_{\mathrm{o}}$ influence $I_{\mathrm{NMDA}}$ by controlling the activity of calcineurin, then elevation of brain magnesium might be able to prevent overactivation of calcineurin by high $\mathrm{A} \beta$, resulting in protection of NMDARs. Indeed, in the presence of higher $\left[\mathrm{Mg}^{2+}\right]_{\mathrm{o}}(1.2 \mathrm{mM})$, the amplitude of the $I_{\mathrm{NMDA}}$ current under exogenous $A \beta$ was almost identical to that in 0.8 $\left[\mathrm{Mg}^{2+}\right]_{\mathrm{o}}$ control slices (incubated under $\mathrm{A} \beta$-free and physiological $\left[\mathrm{Mg}^{2+}\right]_{\mathrm{o}}$ conditions; Fig. $6 D$ ). To prove that this protection is mediated by calcineurin, we compared the size of $I_{\mathrm{NMDA}}$ under high $\mathrm{A} \beta$, high/low $\left[\mathrm{Mg}^{2+}\right]_{\mathrm{o}}$, or both in the presence of calcineu- rin inhibitor. $I_{\mathrm{NMDA}}$ was identical in all slices regardless of the presence of high $A \beta$ or $\left[\mathrm{Mg}^{2+}\right]_{\mathrm{o}}$ (Fig. $6 D$ ). Therefore, elevation of brain magnesium might protect NMDARs in the Tg mice by preventing overactivation/overexpression of calcineurin (Fig. 6F),

Finally, in the Tg mice, the NR2B-containing NMDARs were dramatically reduced, whereas MgT treatment prevented such downregulation (Fig. $3 A, B, I, J$ ). To confirm that $\mathrm{A} \beta$ primarily affects synaptic NR2B-containing NMDAR, we studied the effects of $\mathrm{A} \beta$ on $I_{\mathrm{NMDA}}$ after blocking NR2B-containing NMDARs 
A
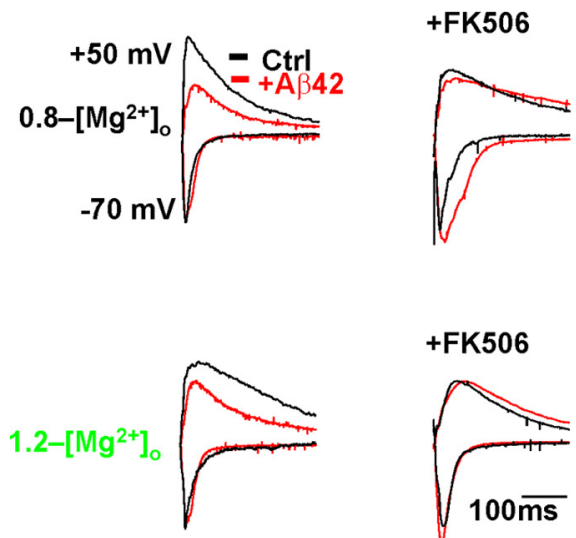

B

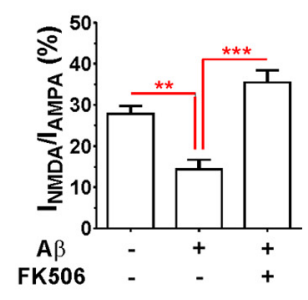

E

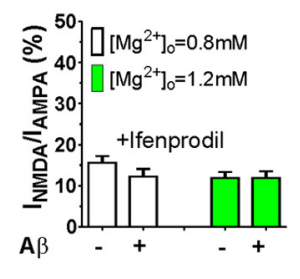

C

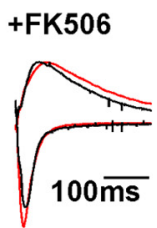

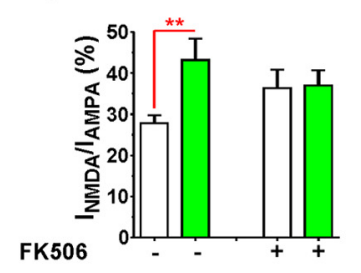

F
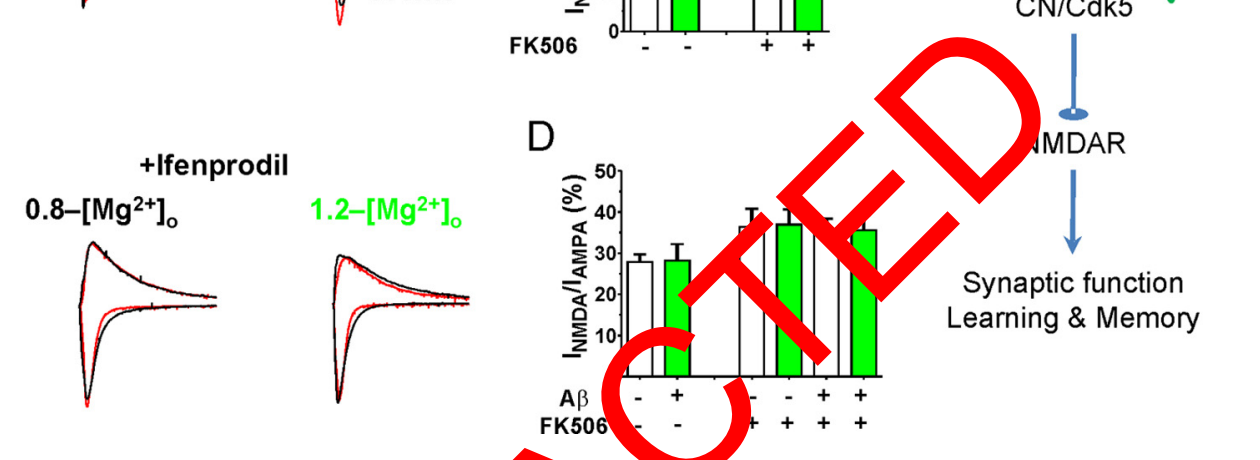

Figure 6. Prevention of exogenous $A \beta 42$-induced downregulation of synaptic NMDAR by try tion of $\left[\mathrm{Mg}^{2+}\right]_{0}$. $\boldsymbol{A}$, Top, Representative traces of EPSCs recorded at membrane potentials of -70 and $+50 \mathrm{mV}$ at $0.8-\left[\mathrm{Mg}^{2+}\right]_{0}$ before (black) and after (red) application of AB42 with rio or writhout (left) the addition of calcineurin inhibitor (FK506). Middle, Same as above but at

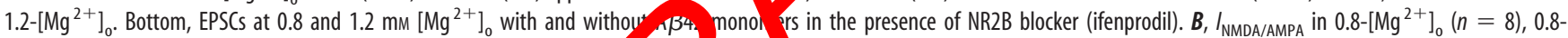

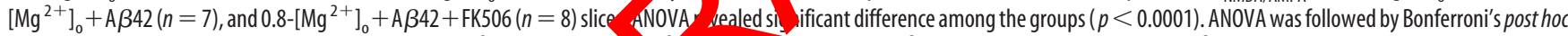

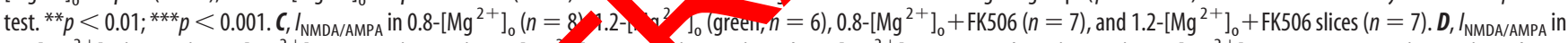
$0.8-\left[\mathrm{Mg}^{2+}\right]_{0}(n=8), 1.2-\left[\mathrm{Mg}^{2+}\right]_{0}+\mathrm{A} \beta 42(n=6), 0.8-\left[\mathrm{Mr}_{0}+\mathrm{FK} 50 \mathrm{~b}=7\right)$, and $1.2-\left[\mathrm{Mg}^{2+}\right]_{0}+$ FK506 slices $(n=7), 0.8-\left[\mathrm{Mg}{ }^{2+}\right]_{0}+\mathrm{A} \beta 42+\mathrm{FK} 506(n=8)$, and $1.2-$ $\left[\mathrm{Mg}^{2+}\right]_{0}+\mathrm{A} \beta 42+\mathrm{FK} 506(n=8) \cdot \boldsymbol{E}_{,} I_{\mathrm{NMDA} / \mathrm{AMPA}}$ after the additi, of ito rodil; $0.8-\left[\mathrm{mg}^{2+}\right]_{0}(n=6), 0.8-\left[\mathrm{Mg}^{2+}\right]_{0}+\mathrm{A} \beta 42(n=10), 1.2-\left[\mathrm{Mg}{ }^{2+}\right]_{0}(n=8)$, and $1.2-\left[\mathrm{Mg}{ }^{2+}\right]_{0}+\mathrm{A} \beta 42(n=12)$. Recordings were conducted in vitro using acute hippocamp rices from $4-\mathrm{h}$ ok-old WT mice. ${ }^{* *} p<0.01$, unpaired $t$ tests. Error bars show SEM. $\boldsymbol{F}$, Schematic illustration of how high $A \beta$ impairs NMDAR and how elevation of $\left[\mathrm{Mg}^{2+}\right]_{0}$ might prevent t' impairment.

with ifenprodil (3 $\mu \mathrm{M}$ for $10 \mathrm{~min}$ pefor ecording). NR2Acontaining NMDARs in $0.8-\mathrm{Mo}_{0}$ ond $1.2-\left[\mathrm{Mg}^{2+}\right]_{0}$ slices were unaffected by $\mathrm{A} \beta$ (Fig. $6 E$ ), ggesting that the reduction of $I_{\mathrm{NMDA}}$ after $\mathrm{A} \beta$ application was larg ly due to reduction of synaptic NR2B-portion of NMDARs, whereas elevated $\left[\mathrm{Mg}^{2+}\right]_{\mathrm{o}}$ prevented this downregulation.

\section{Effects of elevating brain magnesium on amyloid plaques and BACE1 expression}

Having demonstrated that elevating brain magnesium can protect NMDAR signaling, we explored whether elevation of brain magnesium can affect APP metabolism, which might also contribute to the retained cognitive abilities in MgT-treated Tg mice. We first quantified amyloid plaque density using the anti-A $\beta$ antibody 6E10 in the hippocampus and frontal cortex. At 23 months of age, $\sim 12 \%$ of the hippocampal area in Tg mice was occupied by amyloid plaques. MgT treatment (for 17 months) reduced the amyloid plaque area significantly (by $\sim 35.8 \%$; Fig. $7 A$, top). A similar percentage of reduction was observed in the frontal cortex (by $\sim 36 \%$; Fig. $7 A$, bottom). These observations were confirmed by another anti-A $\beta$-antibody $(4 \mathrm{G} 8$, data not shown). We determined the concentrations of $A \beta 42$ and $A \beta 40$ monomers in the CSF of a separate group of Tg mice (14 months old, MgT treatment for 8 months). The concentration of $\mathrm{A} \beta 42$ was elevated in the CSF of Tg mice. Surprisingly, despite the significant reduction in the amyloid plaque density, CSF concentration of both $\mathrm{A} \beta$ monomers was unaltered by $\mathrm{MgT}$ treatment (Fig. 7B).

To study the molecular mechanisms underlying the reduction of amyloid plaques by MgT treatment, we investigated the expression of BACE1 in the three groups of mice. Under basal conditions after electrical stimulation, Tg mice had significantly higher BACE1 expression levels than WT mice (Fig. 7C). Interestingly, MgT treatment prevented overexpression of BACE1 under both basal and stimulated conditions in Tg mice (Fig. 7C; for ANOVA analysis, see Table 3). A similar pattern of expression in the three groups of mice was observed using quantitative Western blot analysis (Fig. 7D, Table 3) after home-cage and environmental-enrichment-based stimulation (brain homogenates from same mice in Fig. 3I-L). To determine whether the reductions in BACE1 by MgT lead to reductions in the synaptotoxic products of BACE1; namely sAPP $\beta$ and $\beta$-CTF (Tamayev et al., 2012), we investigated the expression of human sAPP $\beta$ and $\beta$-CTF in Tg and $\mathrm{Tg}+\mathrm{MgT}$ mice. We found that $\mathrm{Tg}+\mathrm{MgT}$ mice had significantly lower sAPP $\beta$ expression levels than untreated Tg mice after electrical stimulation (Fig. $7 E$ ). These results, obtained by immunostaining, were confirmed by quantitative Western blot analysis after environmental-enrichment-based stimulation (Fig. 
A

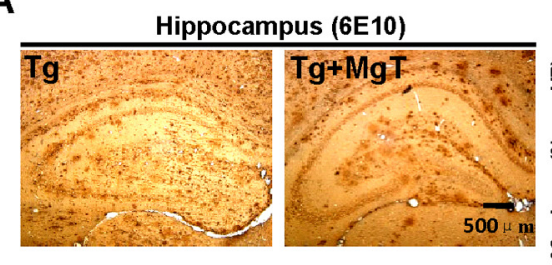

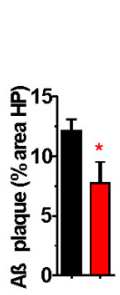

B

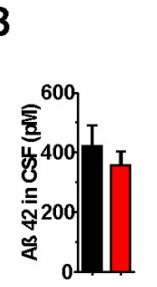

E

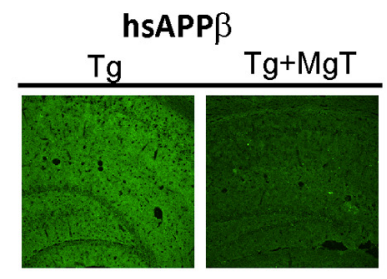

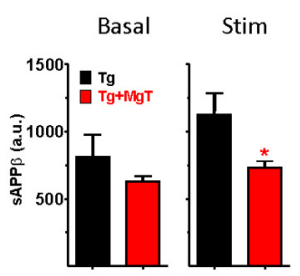
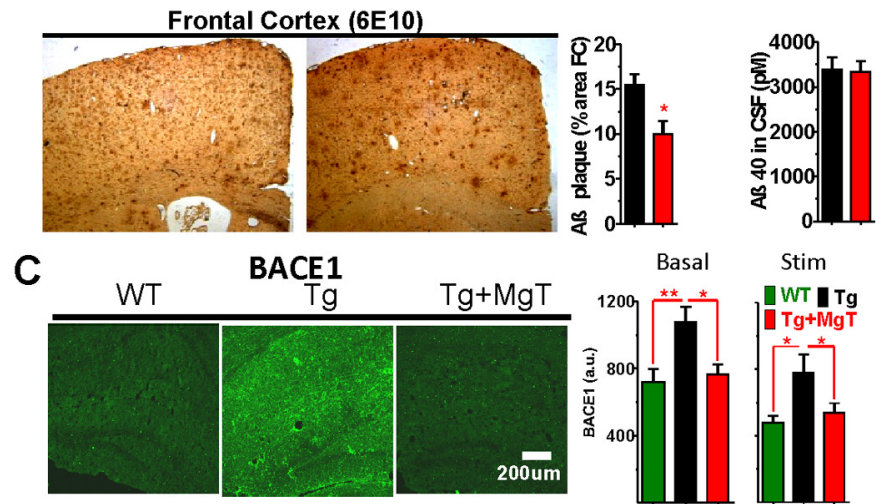

F
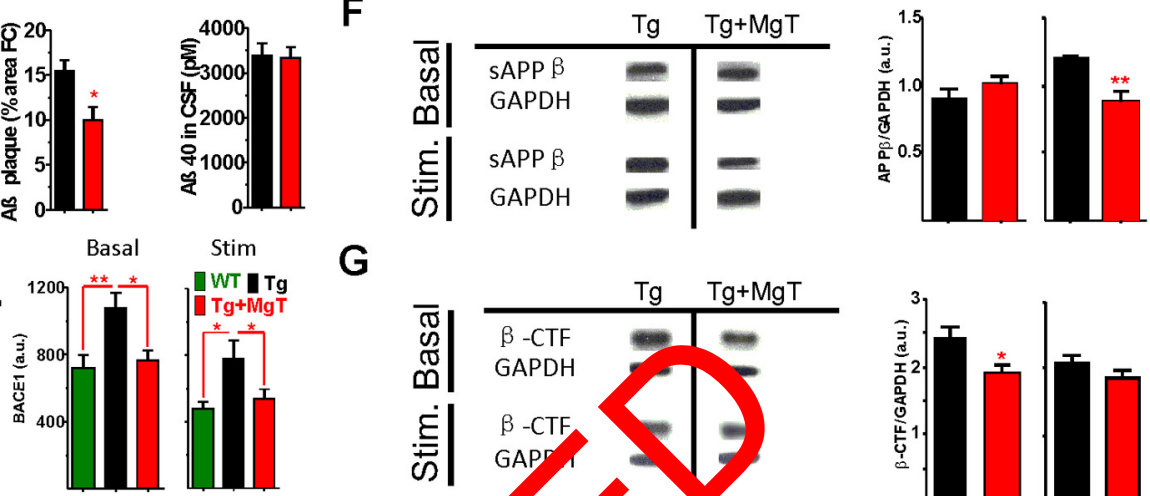

G

\section{.}
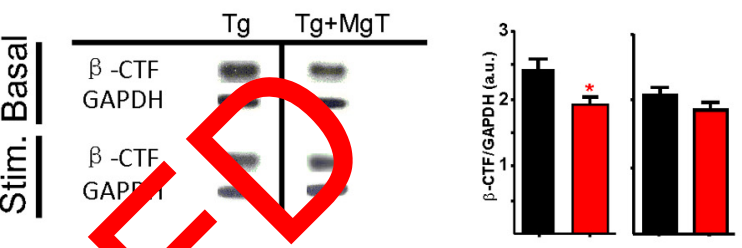

D

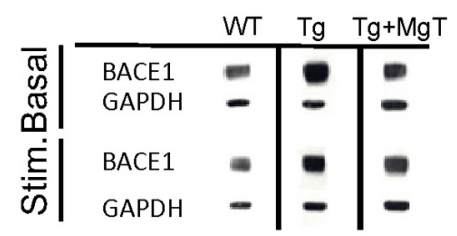

H

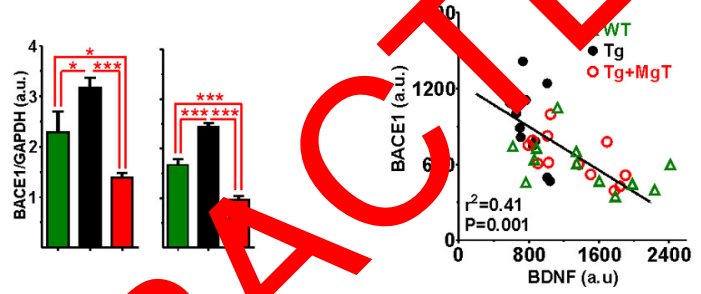

I

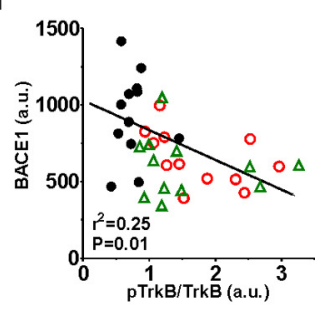

Figure 7. Reductions by MgT treatment in amyloid plaques and BACE1 o expres $5^{\circ}$, hin Tg $n$ e. $A$, Top left, Immunostaining of hippocampal amyloid plaque of $\mathrm{Tg}(n=6)$ and $\mathrm{Tg}+\mathrm{MgT}(n=$ 5). Right: Hippocampal amyloid plaque areas were significantly lower in $g+$. . ice. Boturn: Same as above but in the frontal cortex. ${ }^{*} p<0.05$, two-tailed unpaired $t$ test. $B$, Concentrations of $\mathrm{A} \beta 42$ (top) and $\mathrm{A} \beta 40$ (bottom) monomers in CSF of $\mathrm{Tg}(n=$ and $\mathrm{Tg}+\mathrm{N}(n=15)$ mice measured by ELISA. C, Left, Representative fluorescent images of BACE1 expression in the hippocampus after electrical stimulation. Middle, Quantitative an ulysis. BACE1 exprwssion in DG of WT, $\mathrm{Tg}$, and Tg + MgT mice ( $n=6 / g$ roup) obtained by immunostaining (arbitrary units, a.u.). Mice were perfused under basal conditions without behavior or electrical s, vulation. Right, Quantitative analysis of BACE1 expression in DG of WT, Tg, and Tg + MgT mice ( $n=6 / \mathrm{group}$ ) obtained by immunostaining after in vivo hippocampal electrical mulatio (Stim) $2 \mathrm{~h}$ before perfusion. D, Left, Representative Western blots of BACE1 expression in the hippocampus of mice killed under home-cage conditions (basal) or after $24 \mathrm{~h}$ of environm $\mathrm{tal-g}$,chment-based stimulation (Stim). Middle, Quantitative analysis of BACE1 expression in the hippocampus of WT, Tg, and Tg + MgT mice ( $n=5$ /group) obtained by Western blot 4 rary a s.u. vice were killed under basal conditions without behavioral or electrical stimulation. Right, Quantitative analysis of BACE1 expression in the hippocampus of WT $(n=6, \mathrm{~g}(n=6)$, and MgT mice $(n=5)$ obtained by Western blots after behavioral stimulation. ANOVAs (Table 3) were followed by Bonferroni's post hoc test. $E$, Left, Representative fluorescen ages and $\mathrm{Tg}+\mathrm{MgT}$ mice ( $n=6 /$ group) obtained by . munostaining (arbitrary units, a.u.). Mice were perfused under basal conditions without behavioral or electrical stimulation. Right, Quantitative analysis of hsAPP $\beta$ expression in DG of Tg and Tg MgT mice ( $n=6 /$ group) obtained by immunostaining after in vivo hippocampal electrical stimulation (Stim) $2 \mathrm{~h}$ before perfusion. $\boldsymbol{F}$, Left, Representative Western blots of hSAPP $\beta$ expression in the hippocampus of mice killed under home-cage conditions (basal) or after $24 \mathrm{~h}$ of environmental-enrichment-based stimulation (Stim). Middle, Quantitative analysis of hsAPP $\beta$ expression in the hippocampus of $\mathrm{Tg}$ and $\mathrm{Tg}+\mathrm{MgT}$ mice ( $n=5 / \mathrm{group}$ ) obtained by Western blot (arbitrary units, a.u.). Mice were killed under basal conditions without behavioral or electrical stimulation. Right, Quantitative analysis of hsAPP $\beta$ expression in the hippocampus of $\operatorname{Tg}(n=6)$ and $\operatorname{Tg}+\mathrm{MgT}$ mice $(n=5)$ obtained by Western blots after behavioral stimulation. G, Same as $\boldsymbol{F}$ but for $\beta$-CTF. Two-tailed unpaired $t$ tests were used. $\boldsymbol{H}, \boldsymbol{I}$, Correlation between BDNF expression $(\boldsymbol{H})$ or phosphorylated TrkB $(\boldsymbol{I})$ levels and BACE1 expression in the hippocampus of Tg mice (Pearson's test). Data from WT mice are displayed, but were not included in the analysis. Error bars show SEM. ${ }^{*} p<0.05 ;{ }^{* *} p<0.01{ }^{* * *} p<0.001$.

$7 F)$. In addition, quantitative Western blot analysis showed that $\mathrm{Tg}+\mathrm{MgT}$ mice also had significantly lower $\beta$-CTF levels than untreated Tg mice under basal conditions (Fig. $7 G$ ). Therefore, MgT treatment might reduce the production of APP synaptotoxic metabolites by stabilizing the expression of BACE1 in $\mathrm{Tg}$ mice. These results uncover a new and intriguing potential molecular target of elevated brain magnesium in APP metabolism.

Recent studies have shown that neurotrophins play a critical role in the regulation of BACE1 expression and activity (Costantini et al., 2005; Nikolaev et al., 2009; Devi and Ohno, 2012). For example, activation of BDNF/TrkB signaling downregulated BACE1 expression in a mouse model of sporadic AD (Devi and Ohno, 2012). Because BDNF/TrkB signaling is impaired in $\mathrm{Tg}$ mice and restored by $\mathrm{MgT}$ treatment (Fig. $3 G, H$ ), we investigated whether BDNF/TrkB signaling could influence BACE1 expression. Interestingly, BDNF expression and TrkB activation levels appeared to be inversely correlated with the expression level of BACE1 in in treated and untreated Tg mice (Pearson's test, BDNF: $r^{2}=0.41, p=0.001$; pTrkB: $r^{2}=0.25, p=0.01$; Fig. $7 \mathrm{H}, \mathrm{I})$. Therefore, the elevation of BACE1 in Tg mice might be caused by impairments of BDNF/TrkB signaling, whereas MgT treatment might prevent $\mathrm{BACE} 1$ overexpression by restoring the $\mathrm{BDNF} / \mathrm{TrkB}$ signaling pathway. The detailed molecular mechanisms underlying the stabilization of BACE1 expression by $\mathrm{MgT}$ treatment in $\mathrm{Tg}$ mice, however, require future investigation.

We have shown previously that $\mathrm{MgT}$ treatment upregulates NR2B-containing NMDARs and BDNF/TrkB signaling and increases synapse density in the hippocampus of WT young and 
A

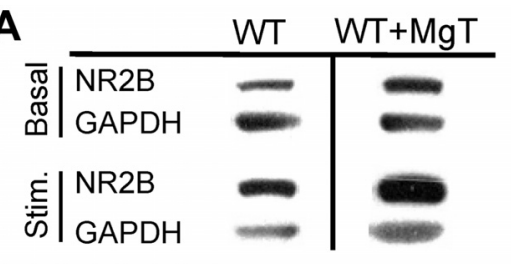

B

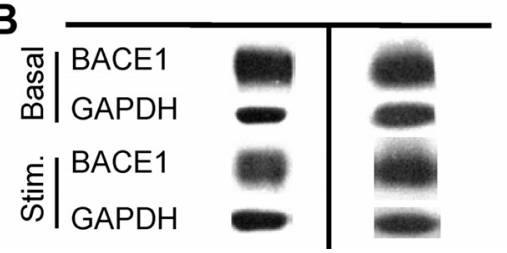

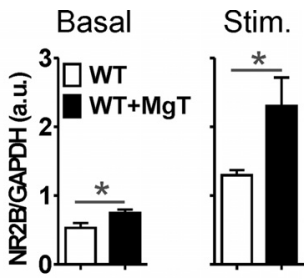

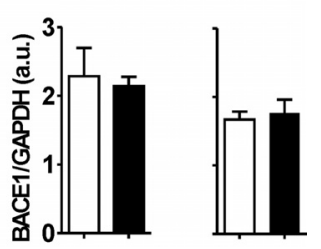

Figure 8. Effects of MgT treatment on expression of NR2B and BACE1 in WT mice. $A$, Left, Representative Western blots of NR2B expression in the hippocampus of WT mice killed under home-cage conditions (basal) or after $24 \mathrm{~h}$ of environmental-enrichment-based stimulation (Stim). Middle, Quantitative analysis of NR2B expression in the hippocampus of WT and WT + MgT mice ( $n=5$ /group) obtained by Western blot (arbitrary units, a.u.). Mice were killed under basal conditions without behavioral or electrical stimulation. Right, Quantitative analysis of NR2B expression in the hippocampus of WT and WT $+M g T$ mice ( $n=6 /$ group) obtained by Western blots after behavioral stimulation. $\boldsymbol{B}$, Left, Representative Western blots of BACE1 expression in the hippocampus of WT mice killed under home-cage conditions (basal) or after $24 \mathrm{~h}$ of environmental-enrichment-based stimulation (Stim). Middle, Quantitative analysis of BACE1 expression in the hippocampus of WT and WT $+\mathrm{MgT}$ mice ( $n=5 /$ group) obtained by Western blot (arbitrary units, a.u.). Mice were killed under basal conditions without behavioral or electrical stimulation. Right, Quantitative analysis of BACE1 expression in the hippocampus of WT and WT+MgT mice ( $n=6 /$ group) obtained by Western blots after behavioral stimulation. Error bars show SEM. * $p<0.05$, two-tailed unpaired $t$ test.

aged rats (Slutsky et al., 2010). The intriguing stabilization o BACE1 expression by MgT prompted us to investig? wh ther this effect of MgT is specific to the Tg mice or if Mg mig regulate BACE1 expression in WT mice. We g antifin the expression of BACE1 and NR2B (as a positive M l) in W mice treated with $\mathrm{MgT}$ (killed at age of 18 mont $^{\text {h }} \mathrm{s}$ after M. T treatment was given for 12 months). Mice were Med under basal (homecage) conditions or after environ a-enrichment-based stimulation. As expected, MgT tr nen upre rated NR2B expression in the hippocampus of W mice 1g. 8A). However, BACE1 expression was indiffo nt otmm WT and WT $+\mathrm{MgT}$ mice under basal conditions an after behavioral stimulation (Fig. $8 B$ ). These results suggest that esvation of brain magnesium stabilizes BACE1 expression only in the Tg mice.

\section{Reversal of learning and memory deficits and synapse loss in aged Tg mice by MgT treatment}

Our previous study demonstrated that elevation of brain magnesium could promote synaptogenesis and enhance NMDAR signaling in aging rats (Slutsky et al., 2010). If synapse loss and dysfunction in NMDAR signaling in $\mathrm{AD}$ is also reversible, then $\mathrm{MgT}$ treatment should be effective at reversing memory deficits even when it is given at the end stage of AD-like pathological progression in Tg mice. To test this possibility, we prepared another group of untreated Tg, tested their memory abilities at 23 month of age, treated them with MgT for 1 month, and reevaluated their memory abilities. As expected, before treatment, Tg mice did not show any preference toward the novel object in the STM and LTM tests, in contrast to aged WT mice (Fig. 9A,B). After 1 month of MgT treatment, strikingly, the same Tg mice exhibited significant improvement in their performance on the memory tests (Fig. 9A, C). To further prove that MgT treatment is effective in restoring cognitive abilities in end-stage $\mathrm{Tg}$ mice, we

evaluated nest construction abilities (a social behavior) in $\mathrm{Tg}$ mice before and after $\mathrm{MgT}$ treatment in a separate group of mice (23 months old). Before MgT treatment, the Tg mice exhibited significant impairment in nest construction behavior compared with aged WT mice ( $p<0.05$; Fig. 9D). After only 1 month of $\mathrm{MgT}$ treatment, nest construction behavior was restored in $\mathrm{Tg}$ mice $(p=0.2$; Fig. $9 E)$. These data demonstrate that learning and memory deficits in Tg mice might be reversible even at the end stage of AD-like pathological progression. However, a limitation of the above behavioral experiments is that the number of animals was relatively low, so any conclusions drawn from these behavioral data might be subject to potential statistical errors. The lower number of animals in the above experiments was due to poor survival of Tg mice during aging (see below), although we prepared a large number of mice at the beginning of the experiments (see Materials and Methods). We took two measures to reduce potential statistical errors. First, cognitive functions were evaluated by using different behavioral tasks. Second, the memory and nesting behayi is we evaluated in the same groups of $\mathrm{Tg}$ mice before and a $\mathrm{MgT}$ ti atment. Such experimental design should give ore co fidep $e$ in the observed effects of MgT in Tg mice.

To dete min thethe recovery of memory and social behavio $\mathrm{Tg} \mathrm{mi}$, associated with restoring the functionality or NM AR signaling, we quantified NR2B and BDNF expr $\mathrm{n}$ in age WT mice and aged Tg mice with 1 month of MgT eatment (perfused at the age of 24 months). The mice were posed $t \quad 24 \mathrm{~h}$ of enriched environment before perfusion to in a ce tration of NMDAR signaling. Strikingly, aged Tg mice ith 1 month of MgT treatment had comparable levels of NR2B and BDNF expression ( $p=0.4$ and 0.3 ; comparison with WT; Fig. $9 F, G$, respectively) compared with aged WT mice. The presynaptic terminal density in hippocampal DG was also restored to a level comparable to that of aged WT ( $p=0.7$; Fig. $9 H$; for ANOVA analysis, see Table 3 ). These data suggest that elevation of brain magnesium reversed the behavioral, structural, and molecular deficits even at the end stage of the AD-like pathological progression in Tg mice.

In addition to the progressive impairment in cognitive abilities, the lifespan of Tg mice was significantly lower than WT. MgT treatment prevented the premature death of Tg mice (Fig. 9I). This longevity with more normal cognitive function highlights the overall beneficial effects of MgT treatment on body health, at least in mice.

\section{Discussion}

In our previous study, we showed that elevation of brain magnesium enhances learning and memory abilities of young and aging rats (Slutsky et al., 2010). Here, we have shown that elevating brain magnesium was effective at preventing/reversing learning and memory deterioration in Tg mice, a model of AD-like pathologies. Comparison of synaptic signaling pathways among $\mathrm{WT}, \mathrm{Tg}$, and $\mathrm{Tg}+\mathrm{MgT}$ mice revealed that downregulation of NMDAR signaling was the major AD-like pathological progression in the Tg mice. The recording studies from hippocampal slices illuminate how elevation of brain magnesium might exert its neuroprotective effects on NMDAR signaling. Unexpectedly, we found that elevation of brain magnesium could prevent dysfunctions in APP metabolism by stabilizing the expression of BACE1 in Tg mice, which might also contribute to the prevention of memory deterioration by $\mathrm{MgT}$ treatment. The most striking finding in the present study was that elevation of brain magnesium was effective at restoring synapse density at the end stage of 
A

\begin{tabular}{|c|c|c|c|c|c|}
\hline $\begin{array}{l}23 \text { months old } \\
\text { WT \& Tg mice }\end{array}$ & $\begin{array}{l}\text { Behavioral } \\
\text { testing }\end{array}$ & $\frac{1 \text { month } \mathrm{MgT}}{\text { for } \mathrm{Tg} \text { mice }}$ & $\begin{array}{l}\text { Behavioral } \\
\text { testing }\end{array}$ & $\underset{\text { Later }}{\stackrel{1 \text { Week }}{\longrightarrow}}$ & $\begin{array}{c}\text { Quantitative protein } \\
\text { analysis }\end{array}$ \\
\hline
\end{tabular}
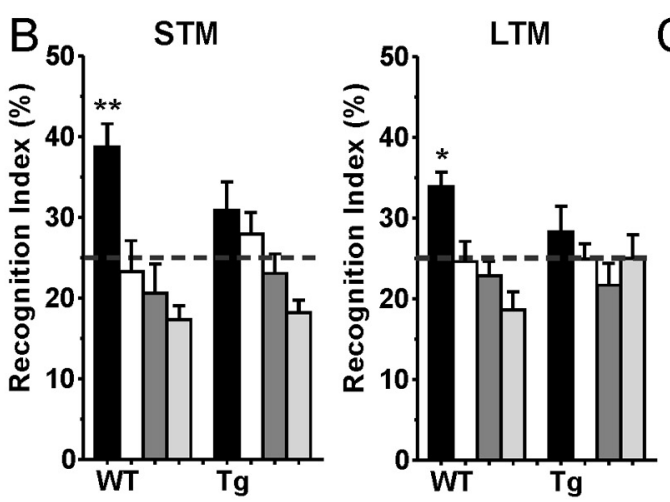

C
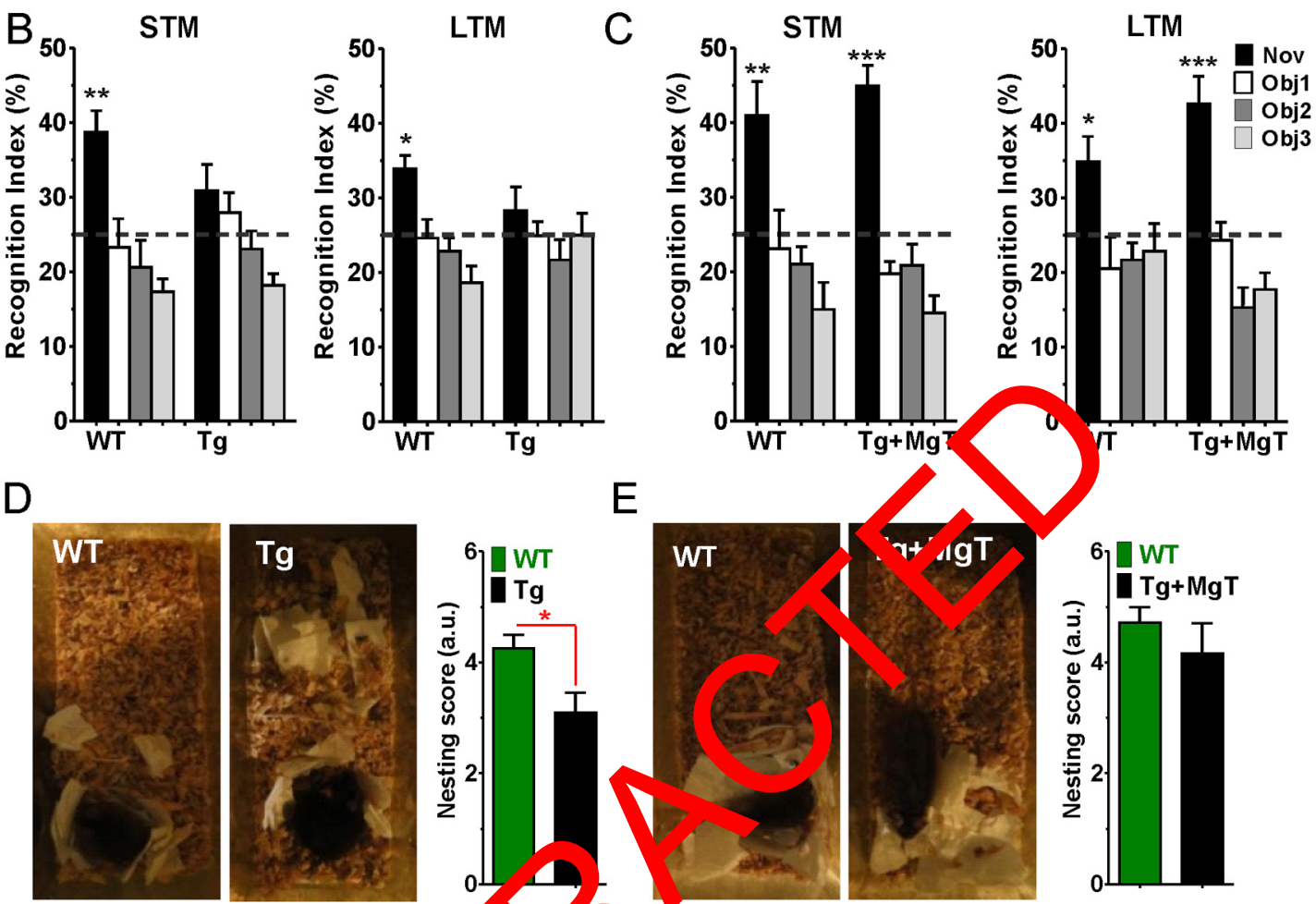

$\mathrm{E}$
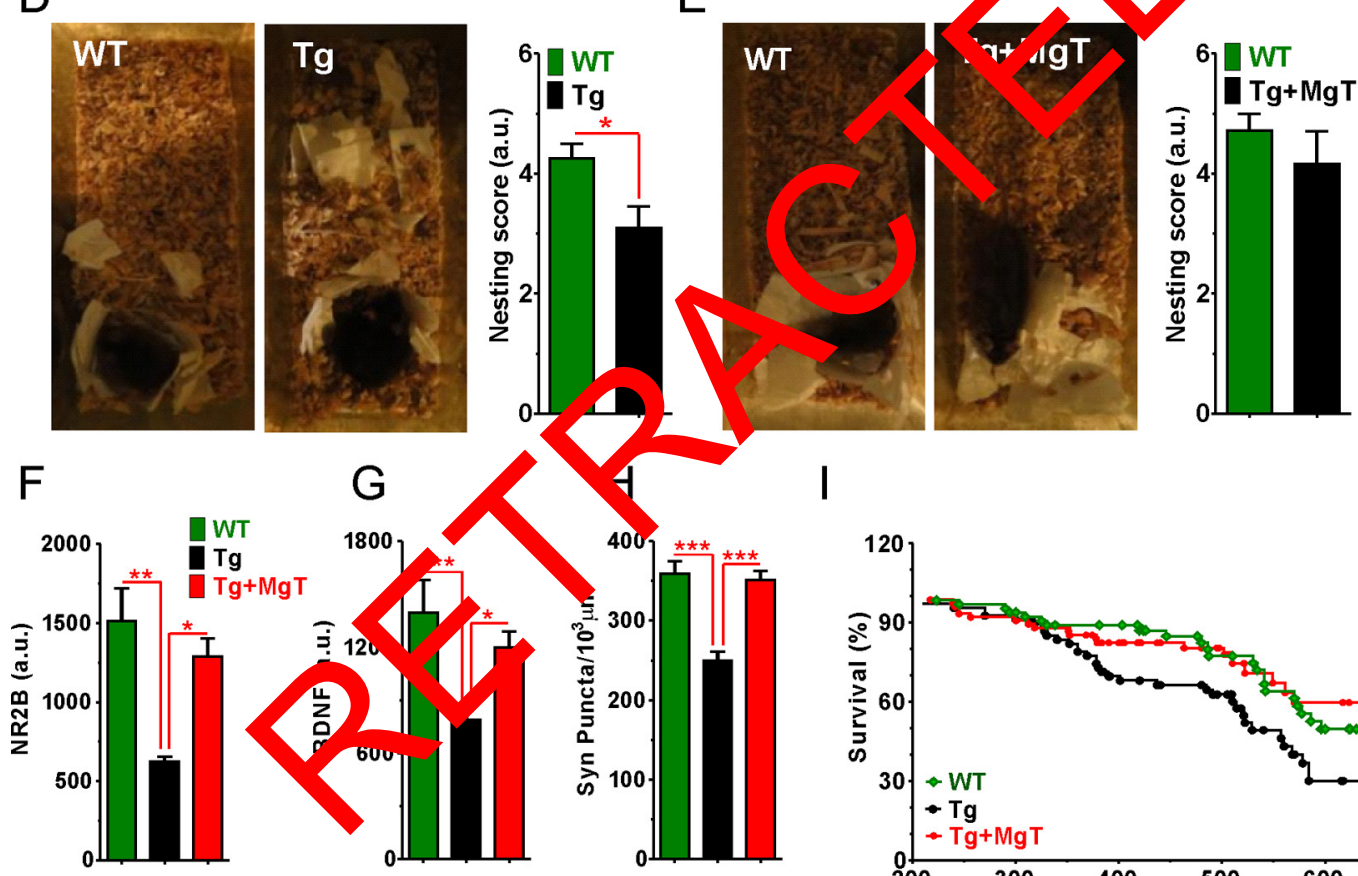

I

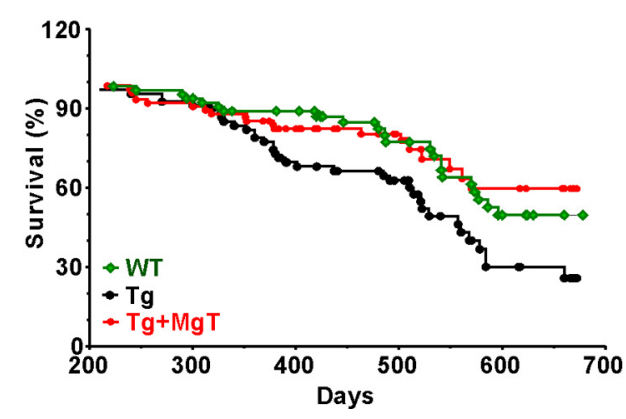

Figure 9. Reversal by MgT treatment of behavioral, molecular, and structural deficits in aged Tg mice and prevention of their premature death. $A$, Experimental design to determine whether MgT treatment can reverse behavioral deficits in aged Tg mice. $\boldsymbol{B}$, Recognition index of the novel object (Nov) and other familiar objects (Obj 1-3) during STM (left) and LTM (right) tests in the NORT task. WT ( $n=10$, ANOVA, STM: $p<0.0001$; LTM: $p<0.0001)$ and untreated Tg $(n=8)$. C, Same as $\boldsymbol{B}$ and on the same mice but NORT tests were reconducted after MgT treatment was given to Tg mice for 1 month. ANOVA revealed significant differences in WT ( $n=8$, STM: $p<0.001$; LTM: $p<0.05)$ and MgT-treated aged Tg mice $(n=7$, STM: $p<0.0001$; LTM: $p<0.0001)$. Dashed lines represent chance levels of performance (25\%). ANOVA was followed by Bonferroni's post hoc test. $\boldsymbol{D}$, Nest construction social behavior in WT $(n=10)$ and untreated Tg mice $(n=10)$. $\boldsymbol{E}$, Same as $D$ and on the same WT $(n=7)$ and $\mathrm{Tg}(n=6)$ mice, but after MgT treatment was given to $\mathrm{Tg}$ for 1 month. $F$, Quantitative analysis of NR2B expression in DG of WT ( $n=8)$ and aged Tg + MgT mice $(n=7)$ obtained by immunostaining (arbitrary units, a.u.). $\mathbf{G}$, Same as $\boldsymbol{F}$ but for BDNF expression. $\boldsymbol{H}$, Density of synaptophysin positive terminals (Syn Puncta). Data from untreated aged Tg mice (Fig. 2B, Fig. 3A,G) were inserted (black bars) to show the effects of the 1 month treatment. ANOVAs (Table 3) were followed by Bonferroni's post hoc test. Error bars show SEM. ${ }^{*} p<0.05 ;{ }^{* *} p<$ 0.01 ; ${ }^{* * *} p<0.001$. I, Survival curves of WT $(n=65), \mathrm{Tg}(n=68)$, and $\mathrm{Tg}+\mathrm{MgT}(n=76)$ mice over the $678 \mathrm{~d}$ of lifespan (MgT treatment started at 6 months of age). A log-rank Mantel-Cox test revealed a significant difference between $\operatorname{Tg}$ mice and WT mice $(p<0.05)$ and $\operatorname{Tg}+\operatorname{MgT}$ mice $(p<0.01)$.

AD-like pathological progression in Tg mice, which might be responsible for the restoration of cognitive functions.

How does elevation of brain magnesium protect NMDAR signaling in Tg mice?

How dysfunctions of APP metabolism lead to synaptic dysfunctions/loss has been studied extensively (Selkoe, 2002). The unique feature of the present study is the systematic evaluation of major signaling pathways implicated in synaptic remodeling and memory processes, such as NMDARs, activity-dependent protein synthesis, and energy supply, under basal conditions and after correlated neuronal activity in vivo.

Among these molecular pathways, the NMDAR signaling pathway is likely to be one of the primary mechanisms underlying 
memory deficits in $\mathrm{Tg}$ mice, because NMDARs play a pivotal role in memory processes (Martin et al., 2000). A recent study showed that protection of NMDARs is sufficient to ameliorate the memory deficits in an animal model of $\mathrm{AD}$ (Cissé et al., 2011). In the present study, NMDAR signaling was dramatically impaired in $\mathrm{Tg}$ mice. This downregulation is likely to be caused by dysfunctions in $\mathrm{Ca}^{2+}$ homeostasis in these mice. Cytosolic $\mathrm{Ca}^{2+}$ level is hypothesized to be elevated during AD pathologies (Bezprozvanny and Mattson, 2008). $\mathrm{A} \beta$ can increase $\mathrm{Ca}^{2+}$ entry into the cell either by functioning as a $\mathrm{Ca}^{2+}$ channel or by activating plasma membrane $\mathrm{Ca}^{2+}$ channels (Alberdi et al., 2010; Jang et al., 2010), which might contribute to elevation of cytosolic $\mathrm{Ca}^{2+}$ levels under basal conditions in $\mathrm{Tg}$ mice (Kuchibhotla et al., 2008). The increase in intracellular basal $\mathrm{Ca}^{2+}$ induces upregulation of calpain/calcineurin/Cdk5 neurodegenerative signaling (Shi et al., 2000). These signaling molecules are known as the major downregulators of NMDARs (for review, seeLau and Zukin, 2007). Therefore, the downregulation of NMDARs by elevated $\mathrm{A} \beta$ might be mediated by the upregulation and/or overactivation of calpain and/or calcineurin (Snyder et al., 2005). In the present study, calpain/calcineurin/Cdk5 expression in $\mathrm{Tg}$ mice was higher than WT, which could underlie the downregulation of NR2B-containing NMDARs.

In MgT-treated Tg mice, the NMDAR signaling pathway and calpain/calcineurin/Cdk5 expression were not different from WT mice. We hypothesize that $\mathrm{Mg}^{2+}$ might inhibit and/or downregulate calpain/calcineurin/Cdk5 to prevent downregulation of NMDAR signaling (Fig. $6 F$ ). In our previous studies, we demonstrated that elevation of $\left[\mathrm{Mg}^{2+}\right]_{\mathrm{o}}$ reduces $\left[\mathrm{Ca}^{2+}\right]_{\mathrm{i}}$ and this associated with NMDAR activation under resting-membrane $p$ tentials (Slutsky et al., 2004). This reduction in $\left[\mathrm{Ca}^{2+}\right.$ homeostatic upregulation of NR2B-containing NMD (Slutsky et al., 2004) and in intact animals (Slutsky the present study, we show that calcineurin is one or rimary molecules mediating the effects of elevatin $\left.{ }_{1}{ }^{2+}\right]_{0}$. b cause both $\mathrm{A} \beta$ and $\left[\mathrm{Mg}^{2+}\right]_{0}$ regulate NMDARs $y$ modu ting the activity of calcineurin, we propose that he protective effects of $\left[\mathrm{Mg}^{2+}\right]_{\mathrm{o}}$ on NMDARs in high $\mathrm{A} \beta$ ba $r$ ror and might be largely mediated by preventing overact ion, vere oression of calcineurin. In support of the role of ove activa on of calcineurin in AD-like pathologies, the inh it 10 alcineurin alone was shown previously to ameliorate $\mathrm{t}, \mathrm{AD}$-like pathologies in an $\mathrm{AD}$ mouse model (Dineley et al., 2007).

\section{How could elevation of brain magnesium lead to downregulation of BACE1?}

Intriguingly, elevation of brain magnesium not only protected NMDAR signaling, but also reduced the expression of BACE1, a critical enzyme that cleaves APP. Recent studies suggest that dysfunctions in APP cleavage by BACE1 might be the primary factor underlying the synapse loss and memory deficits in an $\mathrm{AD}$ mouse model (Tamayev et al., 2012) and that the degeneration of cortical neurons in vitro (Nikolaev et al., 2009). Inhibition (Tamayev et al., 2012) or the partial reduction of expression of BACE1 (Singer et al., 2005; McConlogue et al., 2007) rescues synaptic/ memory deficits in mouse models of AD. Therefore, the reductions in BACE1 expression by MgT treatment could contribute to the prevention of synapse loss and improvement of cognitive function in the Tg mice. In the present study, the exact molecular mechanisms underlying prevention of BACE1 overexpression by $\mathrm{MgT}$ treatment remain elusive. Recent studies suggest that activation of BDNF/TrkB blocks BACE1 overexpression in an $\mathrm{AD}$ mouse model (Devi and Ohno, 2012). Given that MgT treatment restored BDNF/TrkB signaling (Fig. 3G,H) in Tg mice, the prevention of BACE1 overexpression by MgT treatment might simply be a result of restoring BDNF/TrkB signaling. In support of this interpretation, we found that the BACE1 expression level in individual $\mathrm{Tg}$ mice (treated and untreated) was inversely correlated with their BDNF expression and TrkB activation. The exact molecular mechanisms underlying regulation of BACE1 expression/activity by $\mathrm{Mg}^{2+}$ are currently under investigation.

Based on all of the above data, we propose the following nonexclusive scenarios to explain the mechanism underlying the neuroprotective effects of elevating brain magnesium in Tg mice. The APPswe/PS1dE9 genetic manipulation leads to increases in $\mathrm{A} \beta$ concentration in the synaptic cleft, triggering downregulation of NMDARs signaling. The downregulation of NMDAR signaling reduces activity-dependent BDNF release, which subsequently leads to disinhibition of BACE1 activity. This promotes the production of APP synaptotoxic metabolites sAPP $\beta$ and $\beta$-CTF and/or the generation of more $\mathrm{A} \beta$, causing further damage of NMDARs. Thi vicio cycle might ultimately impair NMDAR signaling an synaptic blasticity/remodeling, resulting in synapse loss ar cogn ve dine. Elevation of brain magnesium disrupts ais vi ous a ve by protecting the NMDARs and its downstr am aling athway from these synaptotoxic metabolite Iternat ly elevation of brain magnesium might inhibit ACE directly via unknown mechanisms, which reduces sA $\beta$-CT, and/or $\mathrm{A} \beta$ overproduction and thus their toxic fects on synapses. The latter possibility is less likely, because 8 onths of MgT treatment did not affect the CSF concentration of fro $A \beta$. onomers (Fig. $7 B$ ) and almost life-long treatment with orT reduced the $A \beta$-plaque density (Fig. $7 A$ ) and/or $\operatorname{sAPP} \beta$ (Fig. $7 E, F$ ) in the brain by only $\sim 30-35 \%$.

Based on the above interpretations, we attribute the positive effects of MgT treatment on cognitive abilities in $\mathrm{Tg}$ mice to its protective actions on the NMDAR signaling pathway. However, several studies reported increased incidence of epileptic seizures in $\mathrm{AD}$ patients (Palop and Mucke, 2009) and in mouse models of $\mathrm{AD}$ (Palop et al., 2007). Recently, it was shown that low doses of the antiepileptic drug levetiracetam normalized neuronal activity and reversed cognitive deficits in a mouse model of AD (Sanchez et al., 2012). Acute infusions of high doses of $\mathrm{Mg}^{2+}$, which elevate blood $\mathrm{Mg}^{2+}$ concentration by $\sim 2.5-4$ fold, are effective at reducing seizures acutely in the clinical setting ( $\mathrm{Lu}$ and Nightingale, 2000; Altman et al., 2002). This seizure attenuation is due to direct blockage of presynaptic calcium channels by $\mathrm{Mg}^{2+}$ (Hubbard et al., 1968a, 1968b). Therefore, an alternative interpretation of the positive effects of $\mathrm{MgT}$ treatment is that elevation of brain magnesium increases calcium channel blockage, resulting in reductions in brain seizures. However, for such a mechanism to become effective, the $\mathrm{Mg}^{2+}$ concentration in the blood has to be elevated significantly. In the present study, oral administration of MgT only elevated plasma magnesium by $\sim 0.1 \mathrm{~mm}$ (Fig. $1 G$ ) and brain magnesium by $15 \%$ (Fig. $1 F$ ). Because the gating of NMDARs is very sensitive to elevations of extracellular $\mathrm{Mg}^{2+}$ concentrations (Slutsky et al., 2004), the neuroprotective effects of MgT treatment are more likely to be mediated by its action on NMDARs.

\section{Magnesium concentration and synaptic function}

Our studies demonstrate that an increase in magnesium intake enhances memory in young rats, reverses memory decline in aged rats (Slutsky et al., 2010), and prevents memory deterioration a mouse model of $\mathrm{AD}$ (the present study). However, it is intriguing that after long-term magnesium supplementation, the $\mathrm{Mg}^{2+}$ 
concentration in the CSF only increased by $15 \%$ (Slutsky et al., 2010 ) and the total magnesium in brain increased by $30 \%$ (percentage of Tg mice; Fig. $1 F)$. Can small increases in $\left[\mathrm{Mg}^{2+}\right]_{\mathrm{CSF}}$ have major impact on synapse density? In a separate study, we found that increasing extracellular $\mathrm{Mg}^{2+}$ by $15 \%$ led to an $\sim 50 \%$ increase in synapse density in cultured hippocampal synapses (unpublished observations). These data suggest that hippocampal synapse density might be very sensitive to small changes in extracellular $\mathrm{Mg}^{2+}$ concentrations. Under normal physiological conditions, whole-body magnesium is tightly regulated by kidney function. Daily fluctuation of plasma magnesium associated with food intake is $<0.1 \mathrm{~mm}$ above a baseline of $0.7 \mathrm{~mm}$ (Witkowski et al., 2011). Brain magnesium is supposed to be more stable because the blood-brain barrier isolates the brain from daily fluctuations in blood magnesium. Therefore, despite the high sensitivity of the synapses to $\mathrm{Mg}^{2+}$ concentration, synapse density is likely to be stable under physiological conditions. Conversely, if brain magnesium is reduced under pathological conditions, this might have a profound impact on synapse density and memory function. Interestingly, in the hippocampus of $\mathrm{AD}$ patients, the total magnesium level is reduced by $18 \%$ (Andrási et al., 2005). Therefore, restoration/elevation of brain magnesium in $\mathrm{AD}$ patients might be beneficial for ameliorating the cognitive deficits of $\mathrm{AD}$.

\section{References}

Alberdi E, Sánchez-Gómez MV, Cavaliere F, Pérez-Samartín A, Zugaza JL, Trullas R, Domercq M, Matute C (2010) Amyloid beta oligomers induce $\mathrm{Ca}^{2+}$ dysregulation and neuronal death through activation of ionotropic glutamate receptors. Cell Calcium 47:264-272. CrossRef Medline

Altman D, Carroli G, Duley L, Farrell B, Moodley J, Neilson J, Smith Magpie Trial Collaboration Group. (2002) Do women eclampsia, and their babies, benefit from magnesium sulpha pie Trial: a randomised placebo-controlled trial. Lancet CrossRef Medline

Andrási E, Páli N, Molnár Z, Kösel S (2005) Brain a and phosphorus contents of control and Alzhei, her- $\mathrm{c}$, ased patents. J Alzheimers Dis 7:273-284. Medline

Barbagallo M, Belvedere M, Di Bella G, Dom guez II (2011) Altered ionized magnesium levels in mild-to-moder Al eimer's disease. Magnes Res 24:S115-121. CrossRef Medlin

Bernardo A, Harrison FE, McCord N Lhao , Brus A, Davies SS, Jackson Roberts L 2nd, Mathews PM, 1 tsuol , Briog $Y$, Yu RK, Thompson R, McDonald MP (2009) Eliminat of GD3 synthase improves memory and reduces amyloid-beta plaque loa in transgenic mice. Neurobiol Aging 30:1777-1791. CrossRef Medline

Bezprozvanny I, Mattson MP (2008) Neuronal calcium mishandling and the pathogenesis of Alzheimer's disease. Trends Neurosci 31:454-463. CrossRef Medline

Borchelt DR, Ratovitski T, van Lare J, Lee MK, Gonzales V, Jenkins NA, Copeland NG, Price DL, Sisodia SS (1997) Accelerated amyloid deposition in the brains of transgenic mice coexpressing mutant presenilin 1 and amyloid precursor proteins. Neuron 19:939-945. CrossRef Medline

Cissé M, Halabisky B, Harris J, Devidze N, Dubal DB, Sun B, Orr A, Lotz G, Kim DH, Hamto P, Ho K, Yu GQ, Mucke L (2011) Reversing EphB2 depletion rescues cognitive functions in Alzheimer model. Nature 469: 47-52. CrossRef Medline

Costa-Mattioli M, Sossin WS, Klann E, Sonenberg N (2009) Translational control of long-lasting synaptic plasticity and memory. Neuron 61:10-26. CrossRef Medline

Costantini C, Weindruch R, Della Valle G, Puglielli L (2005) A TrkA-top75NTR molecular switch activates amyloid beta-peptide generation during aging. Biochem J 391:59-67. CrossRef Medline

De Rosa R, Garcia AA, Braschi C, Capsoni S, Maffei L, Berardi N, Cattaneo A (2005) Intranasal administration of nerve growth factor (NGF) rescues recognition memory deficits in AD11 anti-NGF transgenic mice. Proc Natl Acad Sci U S A 102:3811-3816. CrossRef Medline

Devi L, Ohno M (2012) 7,8-dihydroxyflavone, a small-molecule TrkB agonist, reverses memory deficits and BACE1 elevation in a mouse model of
Alzheimer's disease. Neuropsychopharmacology 37:434-444. CrossRef Medline

Dineley KT, Hogan D, Zhang WR, Taglialatela G (2007) Acute inhibition of calcineurin restores associative learning and memory in Tg2576 APP transgenic mice. Neurobiol Learn Mem 88:217-224. CrossRef Medline

Ding Y, Qiao A, Wang Z, Goodwin JS, Lee ES, Block ML, Allsbrook M, McDonald MP, Fan GH (2008) Retinoic acid attenuates beta-amyloid deposition and rescues memory deficits in an Alzheimer's disease transgenic mouse model. J Neurosci 28:11622-11634. CrossRef Medline

Ennaceur A, Delacour J (1988) A new one-trial test for neurobiological studies of memory in rats. 1: Behavioral data. Behav Brain Res 31:47-59. CrossRef Medline

Greer PL, Greenberg ME (2008) From synapse to nucleus: calciumdependent gene transcription in the control of synapse development and function. Neuron 59:846-860. CrossRef Medline

Hawasli AH, Benavides DR, Nguyen C, Kansy JW, Hayashi K, Chambon P, Greengard P, Powell CM, Cooper DC, Bibb JA (2007) Cyclindependent kinase 5 governs learning and synaptic plasticity via control of NMDAR degradation. Nat Neurosci 10:880-886. CrossRef Medline

Holtzman DM, Morris JC, Goate AM (2011) Alzheimer's disease: the challenge of the second centy Transl Med 3:77sr71. CrossRef Medline

Hubbard JI, Jones SF, La a EM 968a) On the mechanism by which calcium and magnes affect th spontaneous release of transmitter from mammalia motor ve te Ainals. J Physiol 194:355-380. Medline Hubbard JI, Jon SF, I dau (1968b) On the mechanism by which calcium and sium affect the release of transmitter by nerve impulses, hysiol 6:75 c. Medline

Jack CB , r, nopman , Jagust WJ, Shaw LM, Aisen PS, Weiner MW, Petersen R Trojanowski JQ (2010) Hypothetical model of dynamic oromarkers o. the Alzheimer's pathological cascade. Lancet Neurol 9:119-128. CrossRef Medline

g H, Arc FT, Ramachandran S, Capone R, Azimova R, Kagan BL, Nussiov R al R (2010) Truncated \{beta\}-amyloid peptide channels provide an alternative mechanism for Alzheimer's Disease and Down syndrome. oc Natl Acad Sci U S A.

Kuchibhotla KV, Goldman ST, Lattarulo CR, Wu HY, Hyman BT, Bacskai BJ (2008) Abeta plaques lead to aberrant regulation of calcium homeostasis in vivo resulting in structural and functional disruption of neuronal networks. Neuron 59:214f-225. CrossRef Medline

Lau CG, Zukin RS (2007) NMDA receptor trafficking in synaptic plasticity and neuropsychiatric disorders. Nat Rev Neurosci 8:413-426. CrossRef Medline

Leung LW (1979) Orthodromic activation of hippocampal CA1 region of the rat. Brain Res 176:49-63. CrossRef Medline

Lu JF, Nightingale CH (2000) Magnesium sulfate in eclampsia and preeclampsia: pharmacokinetic principles. Clin Pharmacokinet 38:305-314. CrossRef Medline

Martin SJ, Grimwood PD, Morris RG (2000) Synaptic plasticity and memory: an evaluation of the hypothesis. Annu Rev Neurosci 23:649-711. CrossRef Medline

Matsuoka Y, Jouroukhin Y, Gray AJ, Ma L, Hirata-Fukae C, Li HF, Feng L, Lecanu L, Walker BR, Planel E, Arancio O, Gozes I, Aisen PS (2008) A neuronal microtubule interacting agent, NAP, reduces tau pathology and enhances cognitive function in a mouse model of Alzheimer's disease. J Pharmacol Exp Ther 325:146-153. CrossRef Medline

McConlogue L, Buttini M, Anderson JP, Brigham EF, Chen KS, Freedman SB, Games D, Johnson-Wood K, Lee M, Zeller M, Liu W, Motter R, Sinha S (2007) Partial reduction of BACE1 has dramatic effects on Alzheimer plaque and synaptic pathology in APP Transgenic Mice. J Biol Chem 282:26326-26334. CrossRef Medline

Minoshima S, Giordani B, Berent S, Frey KA, Foster NL, Kuhl DE (1997) Metabolic reduction in the posterior cingulate cortex in very early Alzheimer's disease. Ann Neurol 42:85-94. CrossRef Medline

Morris RG, Garrud P, Rawlins JN, O'Keefe J (1982) Place navigation impaired in rats with hippocampal lesions. Nature 297:681-683. CrossRef Medline

Nagahara AH, Merrill DA, Coppola G, Tsukada S, Schroeder BE, Shaked GM, Wang L, Blesch A, Kim A, Conner JM, Rockenstein E, Chao MV, Koo EH, Geschwind D, Masliah E, Chiba AA, Tuszynski MH (2009) Neuroprotective effects of brain-derived neurotrophic factor in rodent and primate models of Alzheimer's disease. Nat Med 15:331-337. CrossRef Medline

Nikolaev A, McLaughlin T, O’Leary DD, Tessier-Lavigne M (2009) APP 
binds DR6 to trigger axon pruning and neuron death via distinct caspases. Nature 457:981-989. CrossRef Medline

Palop JJ, Mucke L (2009) Epilepsy and cognitive impairments in Alzheimer disease. Arch Neurol 66:435-440. CrossRef Medline

Palop JJ, Mucke L (2010) Amyloid-[beta]-induced neuronal dysfunction in Alzheimer's disease: from synapses toward neural networks. Nat Neurosci 13:812-818. CrossRef Medline

Palop JJ, Chin J, Roberson ED, Wang J, Thwin MT, Bien-Ly N, Yoo J, Ho KO, Yu GQ, Kreitzer A, Finkbeiner S, Noebels JL, Mucke L (2007) Aberrant excitatory neuronal activity and compensatory remodeling of inhibitory hippocampal circuits in mouse models of Alzheimer's disease. Neuron 55:697-711. CrossRef Medline

Reagan-Shaw S, Nihal M, Ahmad N (2008) Dose translation from animal to human studies revisited. FASEB J 22:659-661. CrossRef Medline

Reger MA, Watson GS, Green PS, Wilkinson CW, Baker LD, Cholerton B, Fishel MA, Plymate SR, Breitner JC, DeGroodt W, Mehta P, Craft S (2008) Intranasal insulin improves cognition and modulates betaamyloid in early AD. Neurology 70:440-448. CrossRef Medline

Reiserer RS, Harrison FE, Syverud DC, McDonald MP (2007) Impaired spatial learning in the APPSwe + PSEN1DeltaE9 bigenic mouse model of Alzheimer's disease. Genes Brain Behav 6:54-65. CrossRef Medline

Ren WJ, Liu Y, Zhou LJ, Li W, Zhong Y, Pang RP, Xin WJ, Wei XH, Wang J, Zhu HQ, Wu CY, Qin ZH, Liu G, Liu XG (2011) Peripheral Nerve Injury Leads to Working Memory Deficits and Dysfunction of the Hippocampus by Upregulation of TNF-alpha in Rodents. Neuropsychopharmacology 36: 979-992. CrossRef Medline

Rockenstein E, Adame A, Mante M, Moessler H, Windisch M, Masliah E (2003) The neuroprotective effects of Cerebrolysin in a transgenic model of Alzheimer's disease are associated with improved behavioral performance. J Neural Transm 110:1313-1327. CrossRef Medline

Roe CM, Mintun MA, D’Angelo G, Xiong C, Grant EA, Morris JC (2008) Alzheimer disease and cognitive reserve: variation of education effect with carbon 11-labeled Pittsburgh Compound B uptake. Arch Neurol 1467-1471. CrossRef Medline

Salter MW, Kalia LV (2004) Src kinases: a hub for NMDA receptor regul tion. Nat Rev Neurosci 5:317-328. CrossRef Medline

Sanchez PE, Zhu L, Verret L, Vossel KA, Orr AG, Cirrito JR, D rdze N IoK, Yu GQ, Palop JJ, Mucke L (2012) Levetiracetam sy pres curonar network dysfunction and reverses synaptic and co sitive deh ts in an Alzheimer's disease model. Proc Natl Acad Sci o S A 09:E2895 2903. CrossRef Medline

Savva GM, Wharton SB, Ince PG, Forster G, N thewaFE, Braynt C; Medical Research Council Cognitive Function a Ang Study. (2009) Age, neuropathology, and dementia. N F-1 M 360:2 $82-2309$. CrossRef Medline
Selkoe DJ (2002) Alzheimer's disease is a synaptic failure. Science 298: 789-791. CrossRef Medline

Selkoe DJ (2011) Alzheimer's disease. Cold Spring Harb Perspect Biol 3.

Shi J, Townsend M, Constantine-Paton M (2000) Activity-dependent induction of tonic calcineurin activity mediates a rapid developmental downregulation of NMDA receptor currents. Neuron 28:103-114. CrossRef Medline

Simpkins KL, Guttmann RP, Dong Y, Chen Z, Sokol S, Neumar RW, Lynch DR (2003) Selective activation induced cleavage of the NR2B subunit by calpain. J Neurosci 23:11322-11331. Medline

Singer O, Marr RA, Rockenstein E, Crews L, Coufal NG, Gage FH, Verma IM, Masliah E (2005) Targeting BACE1 with siRNAs ameliorates Alzheimer disease neuropathology in a transgenic model. Nat Neurosci 8:13431349. CrossRef Medline

Slutsky I, Sadeghpour S, Li B, Liu G (2004) Enhancement of synaptic plasticity through chronically reduced $\mathrm{Ca}^{2+}$ flux during uncorrelated activity. Neuron 44:835-849. CrossRef Medline

Slutsky I, Abumaria N, Wu LJ, Huang C, Zhang L, Li B, Zhao X, Govindarajan A, Zhao MG, Zhuo M, Tonegawa S, Liu G (2010) Enhancement of learning and memory by elevating brain magnesium. Neuron 65:165177. CrossRef Medline

Snyder EM, Nong Y, Almei CG, Pa S, Moran T, Choi EY, Nairn AC, Salter MW, Lombroso PJ, ouras GK Greengard P (2005) Regulation of NMDA receptor affich gy a hyloid-[beta]. Nat Neurosci 8:10511058. CrossR

Sperling RA, Jac CR I Aisen PS (2011) Testing the right target and right drug at righ age. So 1 ransl Med 3:111 cm133. CrossRef Medline

Tamayey Matsuda Arancio O, D’Adamio L (2012) $\beta$ - but not $\gamma$-secretas roteolyss of APP causes synaptic and memory deficits in a ase moda of dementia. EMBO Mol Med 4:171-179. CrossRef Medline

erry RD, A sliah E, Salmon DP, Butters N, DeTeresa R, Hill R, Hansen LA, Katzma R (1991) Physical basis of cognitive alterations in Alzheimer's synapse loss is the major correlate of cognitive impairment. Ann 30:572-580. CrossRef Medline

Verpelli C, Piccoli G, Zibetti C, Zanchi A, Gardoni F, Huang K, Brambilla D, Di Luca M, Battaglioli E, Sala C (2010) Synaptic activity controls dendritic spine morphology by modulating eEF2-dependent BDNF synthesis. J Neurosci 30:5830-5842. CrossRef Medline

Wei F, Qiu CS, Kim SJ, Muglia L, Maas JW, Pineda VV, Xu HM, Chen ZF, Storm DR, Muglia LJ, Zhuo M (2002) Genetic elimination of behavioral sensitization in mice lacking calmodulin-stimulated adenylyl cyclases. Neuron 36:713-726. CrossRef Medline

Witkowski M, Hubert J, Mazur A (2011) Methods of assessment of magnesium status in humans: a systematic review. Magnes Res 24:163-180. CrossRef Medline 